\title{
Three-dimensional Nanoporous Cu-BTC/Graphene Oxide Nanocomposites with Engineered Antibacterial Properties Synthesized via a One-pot Solvosonication Process
}

\author{
Ahmad Allahbakhsh ${ }^{\dagger}, *$, Zeinab Jarrahi ${ }^{\dagger}$, Gholamali Farzi ${ }^{\dagger}$, Amin Shavandi ${ }^{\ddagger}$ \\ ${ }^{\dagger}$ Department of Materials and Polymer Engineering, Faculty of Engineering, Hakim \\ Sabzevari University, Sabzevar, Iran \\ ${ }^{\ddagger}$ BioMatter Unit-École Polytechnique de Bruxelles, Université Libre de Bruxelles, Avenue \\ F.D. Roosevelt, 50-CP 165/61, 1050 Brussels, Belgium
}

\begin{abstract}
$\mathrm{Cu}$-based nanostructures are a well-known class of antibacterial nanomaterials with broad antibacterial properties. In this study, a facile and one-pot solvosonication process is introduced to synthesize $\mathrm{Cu}-\mathrm{BTC} / g$ raphene oxide nanocomposites with controlled morphological and structural properties. The size range of synthesized Cu-BTC nanoparticles is controlled through the synthesis process by adjusting the content of graphene oxide nanosheets in the synthesis precursor solution. A wide range of sizes and morphologies are achieved via this strategy and the size range of $\mathrm{Cu}-\mathrm{BTC}$ nanoparticles from $30-40 \mathrm{~nm}$ to $15-20 \mathrm{~nm}$ are obtained by increasing the content of graphene oxide in the precursor solution from 0.005 to $0.15 \mathrm{mg} / \mathrm{ml}$. We believe an increase in the number of available sites on the basal plane of graphene oxide for the nucleation of $\mathrm{Cu}-\mathrm{BTC}$ nanocrystals is the main reason for the smaller size range of $\mathrm{Cu}$-BTC nanoparticles with higher concentrations of graphene oxide in the precursor solution. Moreover, the antibacterial activities of the $\mathrm{Cu}-\mathrm{BTC} /$ graphene oxide nanocomposites are also
\end{abstract}

\footnotetext{
*Corresponding author. Tel: +98 514401 2768. E-mail: a.allahbakhsh@hsu.ac.ir (Ahmad Allahbakhsh)
} 
directly affected by the structure and morphology of $\mathrm{Cu}-\mathrm{BTC}$ nanoparticles on the basal plane of graphene oxide nanosheets. The synthesized nanocomposite with the smallest size range of $\mathrm{Cu}-\mathrm{BTC}$ nanoparticles presents the highest antibacterial activity. Consequently, the results presented here suggest that the antibacterial activity of $\mathrm{Cu}-\mathrm{BTC} /$ graphene oxide nanocomposites can be engineered by controlling the structural and morphological properties of $\mathrm{Cu}-\mathrm{BTC}$ nanoparticles through the synthesis process.

Keywords: Antibacterial nanomaterials; Cu-BTC nanoparticles; Nanocomposites; Graphene oxide; Solvosonication.

\section{Introduction}

Bacterial infections are serious problems that can lead to different health issues such as the contamination of the drinking water, tissue damage, food spoilage, and implant failure $[1,2]$. Moreover, despite great developments through past decades on the treatment of bacterial infections via antibiotics, the ability of microorganisms to develop resistance to antibiotics resulted in a global research interest on the introduction of antibacterial materials and nanomaterials with controlled structures and properties, as well as facile and fast synthesis processes [3]. Although a wide range of antibacterial materials and nanomaterials have been developed and reported in the literature through recent years, the promising antibacterial properties of metal-based nanoparticles and nanostructures have led to a growing interest in the introduction of novel and simple methods for the fabrication of antibacterial metal-based nanomaterials and nanostructures [4-6].

Among different antibacterial metal-based nanoparticles and nanostructures, copper-based particles and nanoparticles have attracted great interest due to their broad antibacterial properties and their high potential to damage bacteria's proteins and lipids [7]. Although $\mathrm{Cu}$ is 
generally an inert metal, $\mathrm{Cu}$ ions $\left(\mathrm{Cu}^{+}\right.$and $\left.\mathrm{Cu}^{2+}\right)$ that form through the release of $\mathrm{Cu}$ to an aqueous medium have a high potential to not only damage the bacteria membrane with binding with different organic substances but also provide bacteria toxicity $[8,9]$.

Besides the direct antibacterial applications of $\mathrm{Cu}$ nanoparticles, porous nanostructures such as $\mathrm{Cu}$-based coordination polymers have also received great attention recently for antibacterial purposes $[10,11]$. These porous nanostructures, as the third-generation antibacterial agents, can present advantages such as high specific surface areas, tunable pore and particle size ranges, and adjustable $\mathrm{Cu}$ ion release rates [10].

$\mathrm{Cu}-\mathrm{BTC}$ is one of the main copper ion-containing coordination polymers that can present interesting antibacterial activity in nanoparticle and nanocomposite forms [10]. Recent studies on $\mathrm{Cu} / \mathrm{H}_{3} \mathrm{BTC}$ nanoparticles have confirmed the concentration-depended antibacterial activity of these nanoparticles against $E$. coli and $S$. aureus [12]. Moreover, $\mathrm{Cu}-\mathrm{BTC}$ nanoparticles $(\mathrm{Cu}-$ BTC NPs) can also be incorporated into different nanocomposites to introduce the antibacterial activity to resulting nanocomposites. The incorporation of Cu-BTC NPs in the structure of chitosan films can lead to the formation of antibacterial polymeric films with a slow release of copper ions and reduced cytotoxicity and, as a result, simultaneously kill bacteria and improve vessel regeneration in local infection therapy [1].

Different synthesis processes are available in the literature to fabricate $\mathrm{Cu}$-BTC NPs with different structural and morphological properties $[13,14]$. The synthesis process of Cu-BTC coordination polymers dictates the morphology and the crystal structure of these $\mathrm{Cu}$-based nanoporous materials [15]. The most conventional synthesis process of $\mathrm{Cu}-\mathrm{BTC}$ is the hydrothermal synthesis process, which mostly leads to the formation of $\mathrm{Cu}$-BTC crystals with the octahedral morphology $[13,15]$. However, different morphologies of $\mathrm{Cu}$-based crystals can be synthesized by controlling the synthesis condition [16]. 
$\mathrm{Cu}$-BTC microcrystals can also be synthesized on the basal plane of graphene oxide (GO) nanosheets to fabricate $\mathrm{Cu}-\mathrm{BTC} / \mathrm{GO}$ nanocomposites [17]. Generally, there is no data on the antibacterial properties of this new class of nanocomposite. However, a recent study on the antibacterial properties of $\mathrm{CuO}$ NPs/GO nanocomposites has revealed that $\mathrm{CuO}$ NPs synthesized on GO nanosheets' surface can significantly improve the inhibiting performance of GO nanosheets against E. coli and $S$. typhimurium bacteria [2].

In this work, $\mathrm{Cu}-\mathrm{BTC} / \mathrm{GO}$ nanocomposites with different morphologies are synthesized through a new solvothermal synthesis process with different contents of GO nanosheets in the precursor solution of the synthesis process. Structural and morphological studies are used to investigate the impacts of different contents of GO in the synthesis precursor solution on the structure and morphology of synthesized nanocomposites. Moreover, the antibacterial properties of synthesized nanocomposites are studied against E. coli and S. aureus. Our results revealed that the antibacterial activity of $\mathrm{Cu}-\mathrm{BTC} / \mathrm{GO}$ nanocomposites can be improved by adjusting the morphology and size of Cu-BTC NPs via controlling the content of GO nanosheets in the solvothermal synthesis precursor solution. The main advantage of the protocol presented in this work for the fabrication of $\mathrm{Cu}-\mathrm{BTC} / \mathrm{GO}$ nanocomposites is the control over the morphology and structure of synthesized nanocomposites that affects the antibacterial activity of final products.

\section{Experimental}

\subsection{Materials}

Graphite powder was from LECO Co. Moreover, potassium permanganate $\left(\mathrm{KMnO}_{4}\right)$, sulfuric acid $\left(98 \%, \mathrm{H}_{2} \mathrm{SO}_{4}\right)$, hydrogen peroxide $\left(30 \%, \mathrm{H}_{2} \mathrm{O}_{2}\right)$, hydrogen chloride $(37 \%, \mathrm{HCl})$, copper 
acetate $\left(\mathrm{Cu}\left(\mathrm{CH}_{3} \mathrm{COO}\right)_{2} \cdot \mathrm{xH}_{2} \mathrm{O}\right)$, benzene tricarboxylic acid (BTC), dimethyl sulfoxide (DMSO), and N,N-dimethylformamide (DMF) were from Merck Chemicals Co.

\subsection{Synthesis of graphene oxide $(G O)$}

GO nanosheets were synthesized using graphite powder as the precursor based on the modified Hummers technique $[1,2]$. In a typical synthesis process, $1 \mathrm{~g}$ of graphite powder was mixed with $100 \mathrm{~mL}$ of $\mathrm{H}_{2} \mathrm{SO}_{4}$ using a magnetic stirrer at room temperature. Then, to oxidize graphite powder, $6 \mathrm{~g}$ of $\mathrm{KMnO}_{4}$ was gradually added to the mixture and was kept at $75-80{ }^{\circ} \mathrm{C}$ for $4 \mathrm{~h}$. Then, $300 \mathrm{~mL}$ of distilled water was added and the mixture was further agitated at room temperature using a magnetic stirrer. To terminate the oxidation reaction, $50 \mathrm{~mL}$ of $\mathrm{H}_{2} \mathrm{O}_{2}$ was added to the mixture after 15 min of stirring. The product was washed with $10 \% \mathrm{HCl}$ solution (5 times) and distilled water (5 times) via centrifugation to reach the neutral $\mathrm{pH}$. The obtained graphite oxide powder was dispersed in the desired concentrations $(0.005,0.05,0.1$, and 0.15 $\mathrm{mg} / \mathrm{mL})$ in distilled water by sonication using a Hielscher UP400S homogenizer $(20 \mathrm{kHz}, 400$ $\mathrm{W}, 80 \%$ power). The GO suspensions were then centrifuged to remove aggregates and unstable particles.

\subsection{Synthesis of copper-based metal-organic nanoparticles and nanocomposites}

A one-pot solvosonication process was employed for the fabrication of $\mathrm{Cu}$-based metal-organic nanoparticles (Cu-BTC NPs) and Cu-BTC/GO nanocomposites. In a typical synthesis process of Cu-BTC NPs, $0.199 \mathrm{gr}(1 \mathrm{mmol})$ of copper acetate and $0.105 \mathrm{gr}(0.5 \mathrm{mmol})$ of BTC were dissolved in a solution of $15 \mathrm{ml}$ of DMF and $15 \mathrm{ml}$ of distilled water. The mixture was sonicated for 45 min using an ultrasonic bath (Free 9 Tecno-Gaz, $300 \mathrm{~W}, 50 \mathrm{~Hz}$ ). The synthesized 
precipitates were filtered and washed three times with DMF. The obtained powders were then dried at room temperature.

$\mathrm{Cu}-\mathrm{BTC} / \mathrm{GO}$ nanocomposites were synthesized by adding $0.199 \mathrm{gr}$ of copper acetate and 0.105 gr of BTC to a solution consisting of $15 \mathrm{ml}$ of DMF and $15 \mathrm{ml}$ of the GO suspension with a specific concentration of GO. The mixture was then sonicated for $45 \mathrm{~min}$. The precipitates were filtrated, washed, and dried at room temperature. The concentration of GO nanosheets in the GO suspensions used for the synthesis of $\mathrm{Cu}-\mathrm{BTC} / \mathrm{GO}$ nanocomposites were 0.005 (NC-1), 0.05 (NC-2), 0.1 (NC-3), and $0.15 \mathrm{mg} / \mathrm{mL}$ (NC-4), as reported in Table 1. A schematic of the protocol followed in this study for the fabrication of samples is presented in Figure 1.

Table 1. GO content in the precursor solutions used for the synthesis of nanocomposites

\begin{tabular}{|l|l|l|l|l|l|}
\hline Sample & Cu-BTC NPs & NC-1 & NC-2 & NC-3 & NC-4 \\
\hline GO content $(\mathrm{mg} / \mathrm{mL})$ & 0 & 0.005 & 0.05 & 0.1 & 0.15 \\
\hline
\end{tabular}

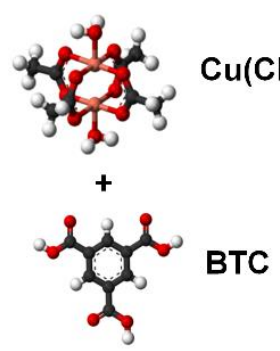

Graphene oxide (GO)
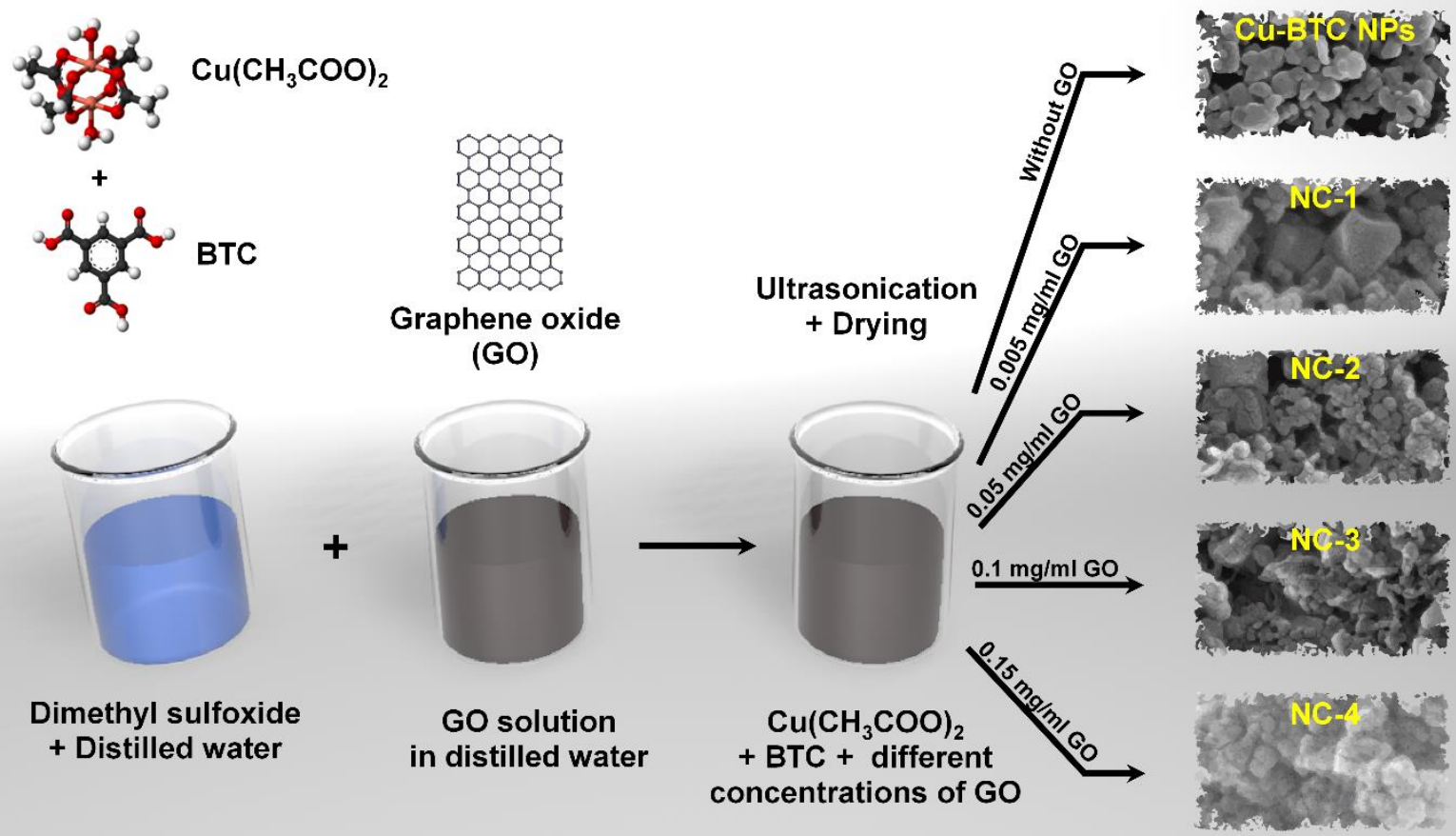

Figure 1. Synthesis protocol: a schematic of the protocol followed in this study for the synthesis of samples 


\subsection{Characterization}

Atomic force microscopy (AFM) results were obtained via a Dualscope DS 95-200, DME atomic force microscope on a freshly cleaved mica substrate. A scan rate of $20 \mu \mathrm{m} / \mathrm{s}$ on the noncontact mode was used and the microscope was equipped with a rectangular cantilever with aluminum coating. Transmission electron microscopy (TEM) images were provided using a Philips CM10 electron microscope $(100 \mathrm{kV})$. Fourier transform infrared (FTIR) spectra were obtained using a Nicolet IR100 spectrometer according to the ASTM E 1252-98. X-ray diffraction (XRD) analyses were carried out using an Inel Equinox 3000 diffractometer equipped with a $\mathrm{Cu} k \alpha$ radiation source $(\lambda=1.54056 \AA)$ at $40 \mathrm{kV}$ and $30 \mathrm{~mA}$. The field emission scanning electron microscopy (FESEM) images were carried out via a TESCAN Mira 3 scanning electron microscope $(15 \mathrm{kV})$.

Nitrogen adsorption/desorption isotherms were provided using a Micromeritics TriStar II Plus instrument at $77 \mathrm{~K}$. Brunauer, Emmett and Teller (BET), Barrett, Joyner, and Halenda (BJH) and t-plot theories were fitted on isotherms to calculate textural parameters. Moreover, singlepoint BET analyses were carried out using a ChemBET 3000 Chemisorption Analyzer at a detector current of $150 \mathrm{~mA}$. Raman spectra were recorded on a LabRAM HR Evolution Raman spectrometer at $532 \mathrm{~nm}$. In addition, dynamic light scattering (DLS) and zeta potential measurements were carried out on a Microtrac Nanotrac Wave II at $25{ }^{\circ} \mathrm{C}$ (solvent: water, the refractive index of the solvent: $\mathrm{n}=1.33$ ).

The antibacterial behavior of fabricated samples was investigated using the micro-well diffusion method described in the literature [12]. Gram-negative Escherichia coli (E. coli ATCC 10536) and Gram-positive Staphylococcus aureus (S. aureus - ATCC 29737) bacteria were used here to investigate the antibacterial behavior of the samples through the agar well diffusion assay [18]. First, each microorganism was grown in a $100 \mathrm{ml}$ conical flask with 10 
$\mathrm{ml}$ of tryptic soy broth (TSB, Merck) on a rotary shaker at $37{ }^{\circ} \mathrm{C}$ for $5 \mathrm{~h}$ at $200 \mathrm{rpm}$. The bacteria was then diluted to $10^{4}-10^{5} \mathrm{CFU} / \mathrm{ml}$ for further studies.

Micro-well dilution assay was used to calculate the minimum inhibitory concentration (MIC) of each sample for E. coli and S. aureus bacteria [12]. In a typical assay, $100 \mathrm{ml}$ of a bacterial suspension $\left(10^{4}-10^{5} \mathrm{CFU} / \mathrm{ml}\right)$ was added to a micro-well (6 $\mathrm{mm}$ in diameter). Different concentrations of samples $(3 \mathrm{mg}, 2 \mathrm{mg}, 1 \mathrm{mg}, 0.5 \mathrm{mg}, 0.25 \mathrm{mg}, 0.125 \mathrm{mg}, 62.5 \mu \mathrm{g}$, and 3.125 $\mu \mathrm{g})$ were added to different wells containing different bacterial suspensions. Suspensions were then incubated at $37{ }^{\circ} \mathrm{C}$ for $24 \mathrm{~h}$ (Memmert $\mathrm{GmbH}$, INB400) and then the concentration of samples in wells with no visible bacterial growth was considered as the MIC of samples.

Minimum bactericide concentration (MBC) values were defined as the lowest concentration of each sample yielding colony counts $<0.1 \%$ of the initial inoculum [19]. After MIC tests, $5 \mu \mathrm{L}$ of suspensions from wells with no visible bacterial growth was placed on an agar plate (Nutrient Agar, Merck). Plates were then incubated for an additional $24 \mathrm{~h}$ at $37{ }^{\circ} \mathrm{C}$. The minimum concentration of each sample required for colony counts $<0.1 \%$ of the initial inoculum after $24 \mathrm{~h}$ of the subculturing was reported as the MBC of the sample.

For the diameter of the inhabitation zone measurements, $100 \mu \mathrm{L}$ of the diluted bacterial suspension $\left(10^{4}-10^{5} \mathrm{CFU} / \mathrm{ml}\right)$ was first evenly spread over an agar Luria Bertani (LB) plate. A sample suspension in DMSO (3, 0.5, and $0.25 \mathrm{mg} / \mathrm{ml})$ was then placed in wells on LB agar plates via pipette [12]. Inoculated plates were then incubated at $37^{\circ} \mathrm{C}$ for $24 \mathrm{~h}$ and the formation of inhibitory zones around each hole was assessed visually and diameters were measured using a millimeter scale. Measurements were repeated three times to calculate standard deviation values. 


\section{Results and discussion}

\subsection{Characterization of GO nanosheets}

The thickness of synthesized GO nanosheets was investigated using AFM results (Figure 2). GO nanosheets had a mean thickness of around $1.5 \mathrm{~nm}$ (Figure 2a), which was in the thicknessrange of GO reported in the literature $(<2 \mathrm{~nm})[20,21]$. Moreover, the TEM results of synthesized GO nanosheets (Figure 2b) presented a folded structure with wrinkled edges, confirming the low thickness of synthesized nanosheets. FTIR results were used to investigate the functionality of synthesized GO nanosheets (Figure 2c). Bands observed at 3424 and 1717 $\mathrm{cm}^{-1}$ were related to stretching vibrations of $-\mathrm{OH}$ (hydroxyl, $\mathrm{COOH}$, and $\mathrm{H}_{2} \mathrm{O}$, mostly carboxyl groups) and $-\mathrm{C}=\mathrm{O}(\mathrm{COOH}$ groups) bonds on the basal plane and edges of $\mathrm{GO}$ [21-23]. 

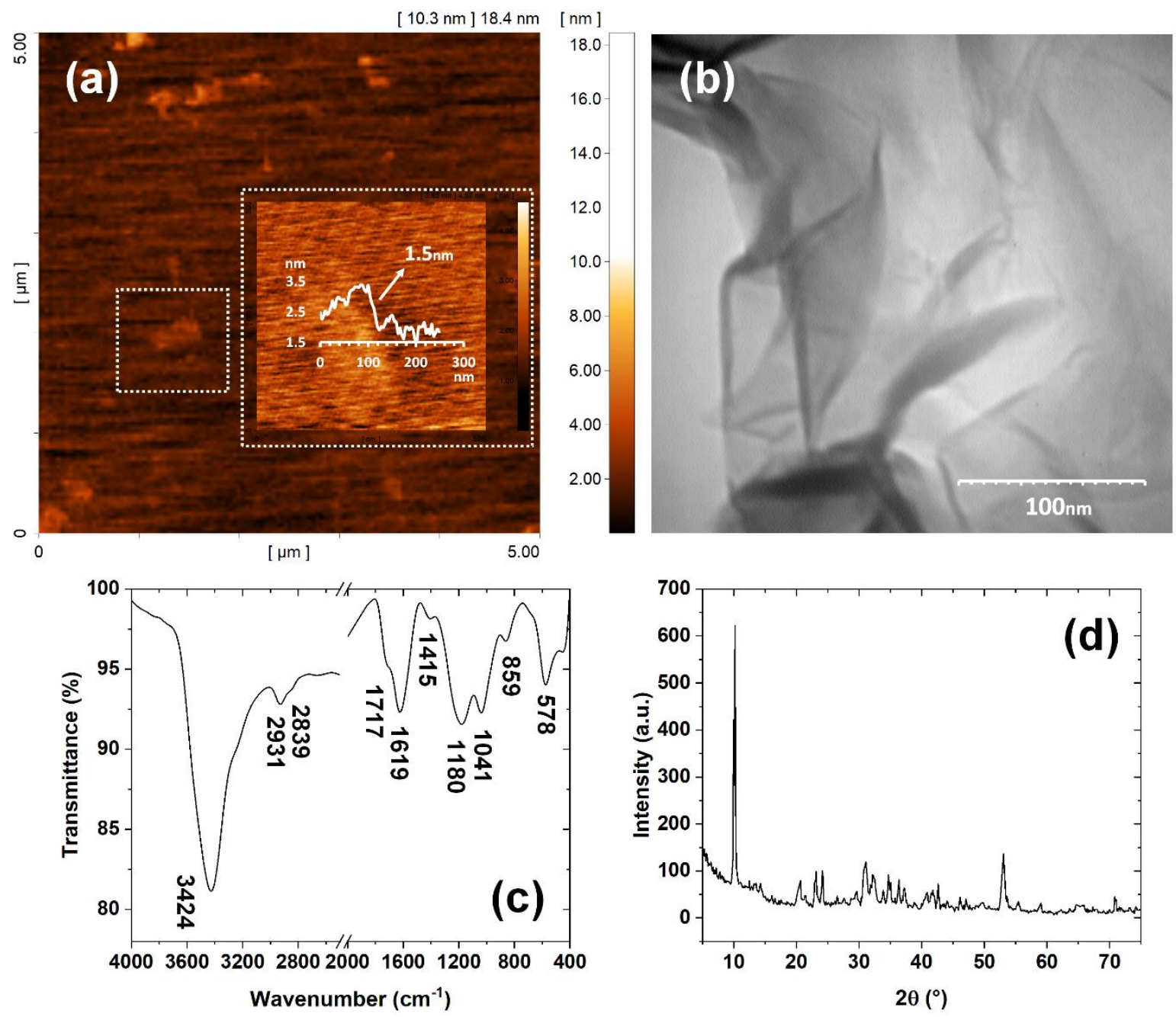

Figure 2. Characterization of GO nanosheets: (a) AFM images, (b) TEM image, (c) FTIR spectrum, and (d) XRD pattern of synthesized GO nanosheets

The band at $1619 \mathrm{~cm}^{-1}$ was assigned to the in-plane asymmetric stretching of sp2-hybridized $\mathrm{C}=\mathrm{C}$ bonding in the backbone of $\mathrm{GO}$ nanosheets (overlapping with $\mathrm{C}=\mathrm{O}$ stretching vibrations of ketones) [24]. Moreover, the band observed at $1415 \mathrm{~cm}^{-1}$ was assigned to the stretching vibrations of C-O $\gamma$-region (mostly epoxides and ketones) [25, 26]. Furthermore, bands at 1041 and $1180 \mathrm{~cm}^{-1}$ were related to $\mathrm{C}-\mathrm{O} \alpha$-region (ethers, hydroxyls, and carboxyls) and $\beta$-region (mostly ketones) stretching vibrations, respectively [21, 25]. Consequently, FTIR results confirmed the successful surface functionalization of GO nanosheets with different oxygencontaining functional groups. Presence of these groups resulted in the observed large interlayer spacing of GO, as observed in the XRD of nanosheets (Figure 2d). The characteristic 
diffraction peak of GO nanosheets was observed at $2 \theta$ values around $10^{\circ}$ [27], corresponding with an interlayer spacing of $0.88 \mathrm{~nm}$.

\subsection{Impacts of the GO content on the morphology of nanocomposites}

Morphological characteristics of the synthesized $\mathrm{Cu}$-based metal-organic nanoparticles $(\mathrm{Cu}-$ BTC NPs) and $\mathrm{Cu}-\mathrm{BTC} / \mathrm{GO}$ nanocomposites synthesized from solvosonication precursor solutions containing 0.005 (NC-1), 0.05 (NC-2), 0.1 (NC-3) and $0.15 \mathrm{mg} / \mathrm{mL}$ (NC-4) GO nanosheets were studied using FESEM images (Figure 3). Cu-BTC NPs synthesized via the solvosonication process presented a semi-spherical nanoparticle-form morphology, similar to the morphology of $\mathrm{Cu}-\mathrm{BTC}$ metal-organic framework (MOF) synthesized by the hydrothermal process using DMF [28], and with ultrasound irradiation under solid-state conditions [29].

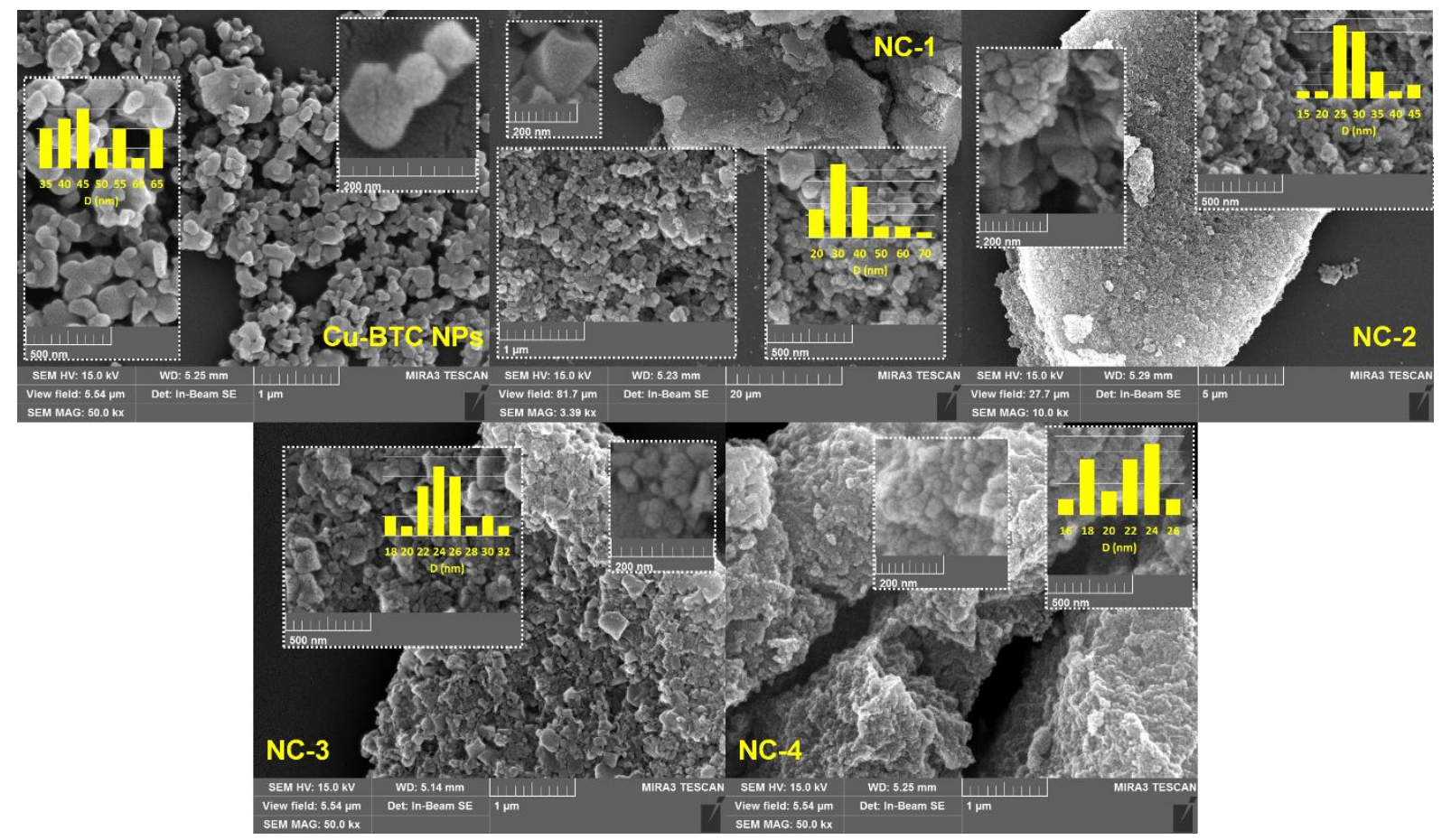

Figure 3. Morphology studies: FESEM images of Cu-BTC NPs and NC samples with different content of GO nanosheets in the precursor solution. NC-1 (0.005 $\mathrm{mg} / \mathrm{ml} \mathrm{GO}), \mathrm{NC}-2(0.05 \mathrm{mg} / \mathrm{ml} \mathrm{GO}), \mathrm{NC}-3(0.1 \mathrm{mg} / \mathrm{ml} \mathrm{GO})$ and $\mathrm{NC}-4(0.15 \mathrm{mg} / \mathrm{ml} \mathrm{GO})$. 
With the incorporation of GO nanosheets, Cu-BTC crystals formed on the surface of GO nanosheets, and a shift in the geometry of Cu-BTC NPs was observed. Interestingly, the shape of the synthesized $\mathrm{Cu}-\mathrm{BTC}$ NPs in the presence of $0.005 \mathrm{mg} / \mathrm{mL}$ GO (NC-1), was similar to the well-known octahedral geometry of HKUST-1 MOF crystals, synthesized via the hydrothermal process [30-32].

As the concentration of GO nanosheets in the precursor solution increased to $0.05 \mathrm{mg} / \mathrm{mL}$ (NC2 in Figure 3), Cu-BTC NPs with both octahedral and semi-spherical morphologies were observed, suggesting a variation in the structure of $\mathrm{Cu}$-BTC NPs with an increase in the concentration of GO in the precursor solution. Interestingly, $\mathrm{Cu}-\mathrm{BTC}$ NPs with common morphologies (such as octahedral and cubic morphologies) were observed to form as a sublayer of $\mathrm{Cu}-\mathrm{BTC}$ NPs with semi-spherical morphologies in the structure of both NC-1 and NC-2. This observation suggests that when the concentration of GO nanosheets in the precursor solution was low $(0.005 \mathrm{mg} / \mathrm{ml}$ in NC-1 and $0.05 \mathrm{mg} / \mathrm{ml}$ in NC-2), first a layer of $\mathrm{Cu}-\mathrm{BTC} \mathrm{NPs}$ with the octahedral morphology formed on the basal plane of GO nanosheets and semispherical Cu-BTC NPs then nucleated on the surface of this layer (see FESEM images of NC1 and NC-2 in Figure 3).

The morphology of Cu-BTC NPs synthesized in the presence of $0.1(\mathrm{NC}-3)$ and $0.15 \mathrm{mg} / \mathrm{mL}$ (NC-4) GO in the precursor solution was more semi-spherical (see FESEM images of NC-3 and NC-4 in Figure 3), close to the one observed for Cu-BTC NPs synthesized without GO (see FESEM images of Cu-BTC NPs in Figure 3). Moreover, not only the particle diameter of $\mathrm{Cu}-\mathrm{BTC}$ NPs in nanocomposites decreased with an increase in the content of GO in the precursor solution, but also the diameter range distribution of $\mathrm{Cu}-\mathrm{BTC}$ NPs in the structure of nanocomposites became narrower with an increase in the content of GO (see particle diameter size histograms in Figure 3). 
The observed variation in the morphology, size range, and size range distribution of Cu-BTC NPs in the structure of synthesized nanocomposites can be related to the difference in the nucleation of Cu-BTC NPs synthesized with different GO contents in the precursor solution [33]. An increase in the content of GO in the precursor solution may result in the additional sites for the nucleation of $\mathrm{Cu}$-BTC NPs, which resulted in the homogeneous distribution of $\mathrm{Cu}$ BTC NPs throughout the surface of GO nanosheets and narrow size distribution of Cu-BTC NPs [34]. Consequently, the morphology of synthesized nanocomposites was related to the content of GO nanosheets in the precursor solution.

\subsection{Microstructural studies}

$\mathrm{N}_{2}$ adsorption/desorption results of Cu-BTC NPs, NC-2, and NC-4 (as model samples) were used to investigate the texture of synthesized samples (Figure 4). The isotherm of synthesized Cu-BTC NPs was a Type-IV adsorption isotherm with a small hysteresis, indicating the formation of a mostly mesoporous structure (inset in Figure 4 for BJH results). The BET surface area of synthesized Cu-BTC NPs $\left(244 \mathrm{~m}^{2} / \mathrm{g}\right)$, was lower than the surface area of CuBTC NPs synthesized via hydrothermal and solid-state synthesis processes $\left(>1000 \mathrm{~m}^{2} / \mathrm{g}\right)[35$, 36] and also lower than the surface area of $\mathrm{Cu}-\mathrm{BTC} / \mathrm{GO}$ nanocomposites (Table 2). However, an increase in the content of GO nanosheets in the precursor solution resulted in a decrease in the surface area of the samples (Table 2). Moreover, the average pore size of the Cu-BTC NPs sample was around $22.7 \AA$, which was close to the reported average pore size of microporous $\mathrm{Cu}-\mathrm{BTC}$ NPs in the literature $[37,38]$. Interestingly, the average pore size of the NC-2 sample was lower than the $\mathrm{Cu}$-BTC NPs sample, and closer to the theoretical average pore size of $\mathrm{Cu}$ BTC nanocrystals (9 $\AA[35,36])$. This behavior can be related to the discussed difference between the morphological behavior of $\mathrm{Cu}$-BTC NPs synthesized without GO in the precursor solution (Cu-BTC NPs in Figure 3) and with a low concentration of GO in the precursor solution (NC-1 and NC-2 in Figure 3). As expected, an increase in the content of GO in the 
precursor solution from $0.05(\mathrm{NC}-2)$ to $0.15 \mathrm{mg} / \mathrm{mL}$ (NC-4) resulted in an increase in the average pore size of the sample to a value close to the Cu-BTC NPs sample (20.4 $)$.

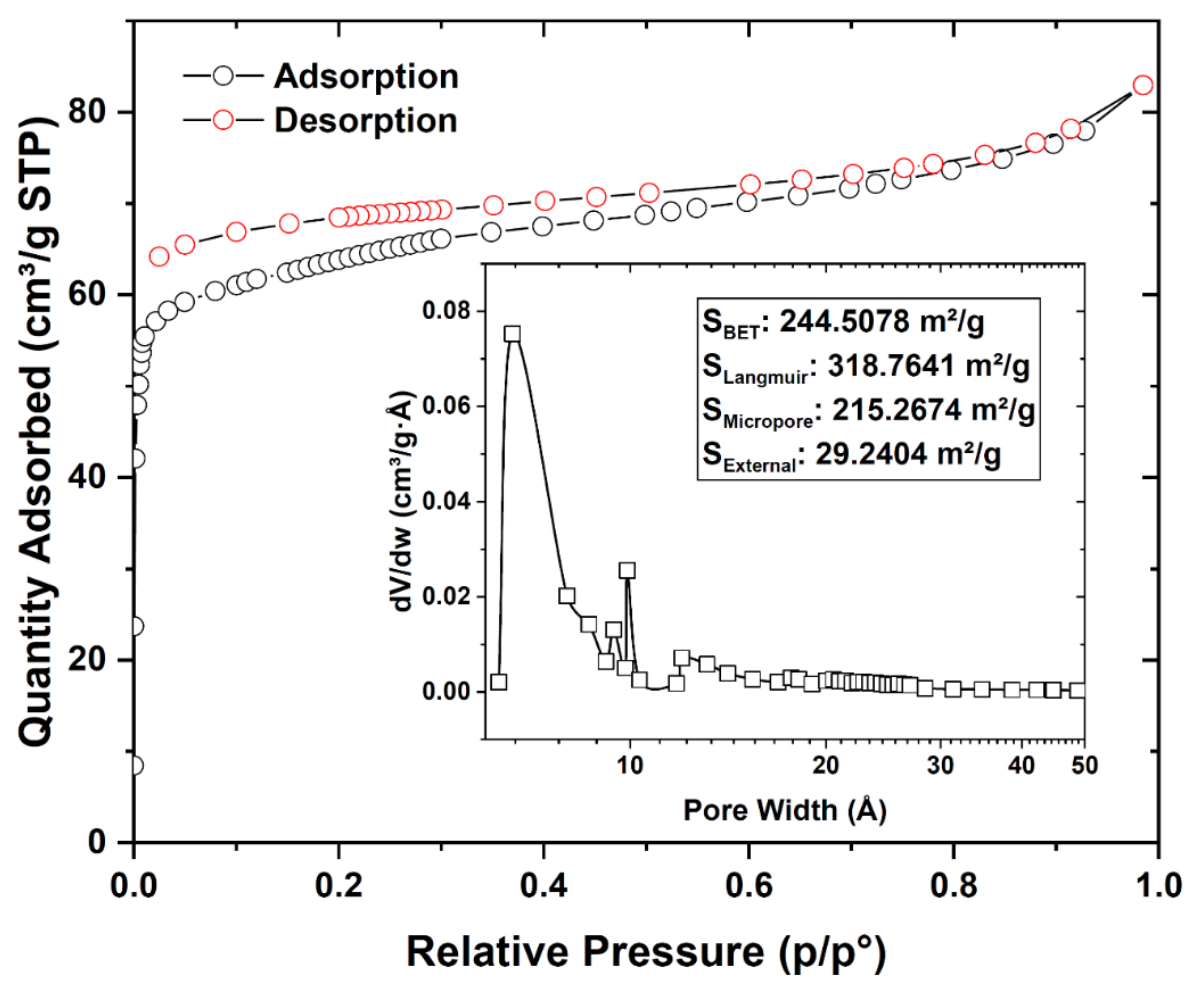

Figure 4. Textural characteristics: $N_{2}$ adsorption-desorption isotherm of the Cu-BTC NPs sample. The inset presents the pore diameter distribution in the structure of the Cu-BTC NPs sample synthesized without GO in the precursor solution.

Table 2. Surface area and pore volume of $C u-C N P s, N C-2$ and $N C-4$ nanocomposites

\begin{tabular}{lllll}
\hline Sample & BET area & Pore volume & Average BET & GO content \\
& $\left(\mathbf{m}^{2} / \mathbf{g}\right)$ & $\left(\mathbf{c m}^{\mathbf{3}} / \mathbf{g}\right)$ & pore size $(\AA)$ & $(\mathbf{m g} / \mathbf{m L})$ \\
\hline Cu-BTC NPs & 244.5 & 0.13 & 22.75 & 0 \\
\hline NC-2 & 775.3 & 0.31 & 15.99 & 0.05 \\
\hline NC-4 & 312.9 & 0.16 & 20.45 & 0.15
\end{tabular}


XRD results were used to further investigate the role of GO content in the precursor solution on the microstructural characteristics of $\mathrm{Cu}-\mathrm{BTC}$ NPs in $\mathrm{Cu}-\mathrm{BTC} / \mathrm{GO}$ nanocomposites (Figure 5). The XRD pattern of Cu-BTC NPs synthesized via solvosonication without GO (Figure 5a) presented a polycrystalline microstructure. The position of main peaks observed in the XRD pattern of $\mathrm{Cu}$-BTC NPs synthesized in this work via the solvosonication process was identical to the position of $\mathrm{Cu}$-BTC MOFs reported in the literature $\left(2 \theta=6.9^{\circ}, 9.5^{\circ}, 11.6^{\circ}, 13.4^{\circ}, 14.9^{\circ}\right.$, $16.6^{\circ}, 17.5^{\circ}, 19.1^{\circ}, 20.1^{\circ}, 23.2^{\circ}, 25.9^{\circ}, 29.4^{\circ}, 35.3^{\circ}$, and $39.1^{\circ}$ ) [39-41]. The relative intensity ratio of the peaks to the intensity of the 440 peak observed in the XRD pattern of Cu-BTC NPs was unlike the common reported XRD pattern for $\mathrm{Cu}-\mathrm{BTC}$ MOFs. This observed XRD pattern was expected, considering that the morphology of Cu-BTC NPs synthesized in this work was semi-spherical and different from the common octahedral morphology of $\mathrm{Cu}-\mathrm{BTC}$ MOFs prepared via the hydrothermal synthesis technique [30-32]. 


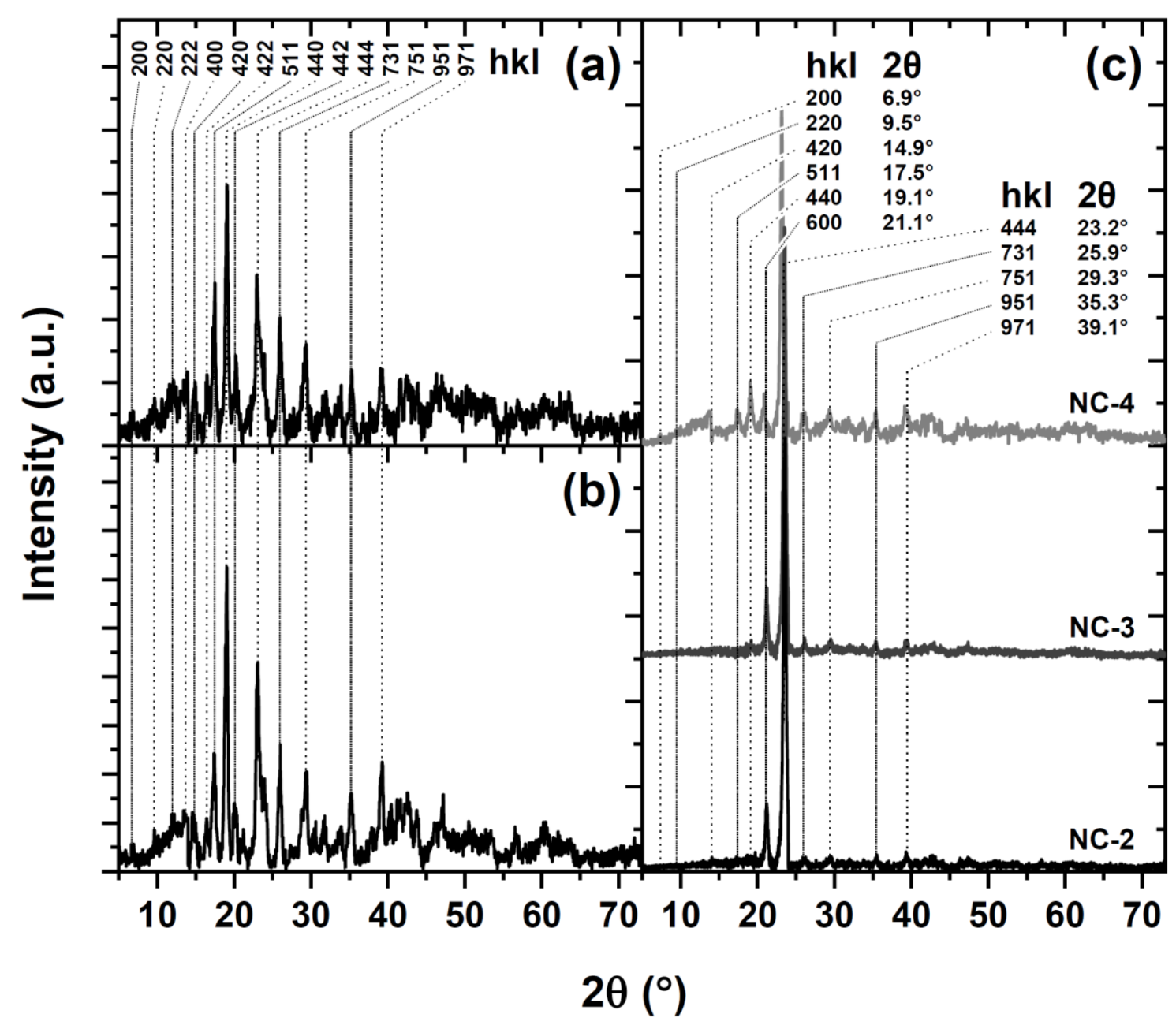

Figure 5. The microstructure of samples: XRD patterns of (a) Cu-BTC NPs and NC samples with different content of GO in the precursor solution. (b) NC-1 (0.005 mg/ml GO), (c) NC-2 (0.05 mg/ml GO), NC-3 (0.1 $\mathrm{mg} / \mathrm{ml} \mathrm{GO})$ and $\mathrm{NC}-4(0.15 \mathrm{mg} / \mathrm{ml} \mathrm{GO})$ nanocomposites.

Presence of GO in the synthesis precursor solution of all synthesized $\mathrm{Cu}-\mathrm{BTC} / \mathrm{GO}$ nanocomposites (Figure $5 \mathrm{~b}$ and c) resulted in the formation of a new crystal lattice plane (i.e., $\left.2 \theta=21.1^{\circ}, \mathrm{hkl}=600\right)$. A similar peak was previously reported in the XRD pattern of HKUST1 crystals synthesized at room temperature using ethanol/water solutions [42]. The intensity of this peak at $21.1^{\circ}$ and the peak observed at $23.2^{\circ}(\mathrm{hkl}=444)$ increased noticeably with an increase in the content of GO in the precursor solution (Figure $5 \mathrm{~b}$ and c). The position of the main XRD peak $\left(2 \theta=23.2^{\circ}\right)$ in Figure $5 \mathrm{c}$ was completely different from the characteristic peak of re-stacked GO nanosheets (expected at $2 \theta$ values around $28^{\circ}$ [43]). Consequently, two structural phenomena can be considered for the appearance of the peak observed at $23.2^{\circ}$ in the 
XRD patterns of $\mathrm{Cu}-\mathrm{BTC} / \mathrm{GO}$ nanocomposites: (i) the partial re-stacking of GO with intercalated Cu-BTC NPs after the synthesis process, and (ii) the formation of Cu-BTC NPs with different microstructural characteristics on the surface of GO nanosheets.

No sign of GO characteristic peaks was observed in the XRD patterns of the synthesized $\mathrm{Cu}-$ BTC/GO nanocomposites (around $10^{\circ}$ in Figure 2d), suggesting the complete exfoliation of GO nanosheets through the synthesis process of $\mathrm{Cu}$-BTC/GO nanocomposites. In addition, the higher specific surface areas of synthesized NC-2 and NC-4 nanocomposites (775 and 312 $\mathrm{m}^{2} / \mathrm{g}$, respectively), compared to the neat synthesized Cu-BTC NPs $\left(244 \mathrm{~m}^{2} / \mathrm{g}\right)$, also confirm the complete exfoliation of GO through the synthesis process. Therefore, the partial re-stacking of GO nanosheets observed in the FESEM images of the NC-4 sample in Figure 3 can only be related to the partial aggregation of $\mathrm{Cu}-\mathrm{BTC} / \mathrm{GO}$ nanocomposites through the drying process.

Interestingly, the microstructure of synthesized NC-4 was close to the Cu-BTC NPs synthesized without GO nanosheets in the precursor (Figure 5a). Most of XRD peaks related to the structure of $\mathrm{Cu}-\mathrm{BTC}$ NPs were observed in the XRD pattern of NC-4 (Figure 5c). Moreover, the intensity of peaks related to the 440 and 511 lattice planes $\left(19.1^{\circ}\right.$ and $17.5^{\circ}$, respectively) increased noticeably in the XRD pattern of $\mathrm{NC}-4$, compared to the peak intensity of 444 and 600 planes $\left(23.2^{\circ}\right.$ and $21.1^{\circ}$, respectively). This structural behavior change suggests the formation of $\mathrm{Cu}-\mathrm{BTC} \mathrm{NPs}$ in the structure of NC-4 with microstructural characteristics close to the $\mathrm{Cu}-\mathrm{BTC}$ NPs synthesized without any GO nanosheets in the precursor solution. Therefore, the microstructure and morphology of Cu-BTC NPs in the structure of $\mathrm{Cu}-\mathrm{BTC} / \mathrm{GO}$ nanocomposites can be engineered by controlling the conditions of the synthesis process.

FTIR results were used to further study the structure of synthesized $\mathrm{Cu}-\mathrm{BTC}$ NPs and $\mathrm{Cu}$ BTC/GO nanocomposites (Figure 6). Main characteristic bands of Cu-BTC NPs were observed at around 1374, 1443, 1581, and $1644 \mathrm{~cm}^{-1}$ in the FTIR spectrum of Cu-BTC NPs 
(Figure 6a). Bands observed at 1443 and $1644 \mathrm{~cm}^{-1}$ were assigned to $-\mathrm{O}-\mathrm{C}-\mathrm{O}-$ bonding (symmetric and asymmetric stretching vibrations, respectively), and the bands at 1374 and $1581 \mathrm{~cm}^{-1}$ were related to $\mathrm{C}=\mathrm{C}$ stretching vibrations in the backbone of BTC in $\mathrm{Cu}-\mathrm{BTC}$ NPs [44-46]. Moreover, bands related to the $\mathrm{Cu}-\mathrm{O}$ bonding in the structure of $\mathrm{Cu}-\mathrm{BTC}$ NPs were observed in the range of $670-770 \mathrm{~cm}^{-1}$, indicating the successful formation of $\mathrm{Cu}$-BTC NPs [44]. The band at $1105 \mathrm{~cm}^{-1}$ is also known to be the characteristic band of $\mathrm{C}-\mathrm{O}-\mathrm{Cu}$ bonding in the structure of Cu-BTC NPs [47, 48].

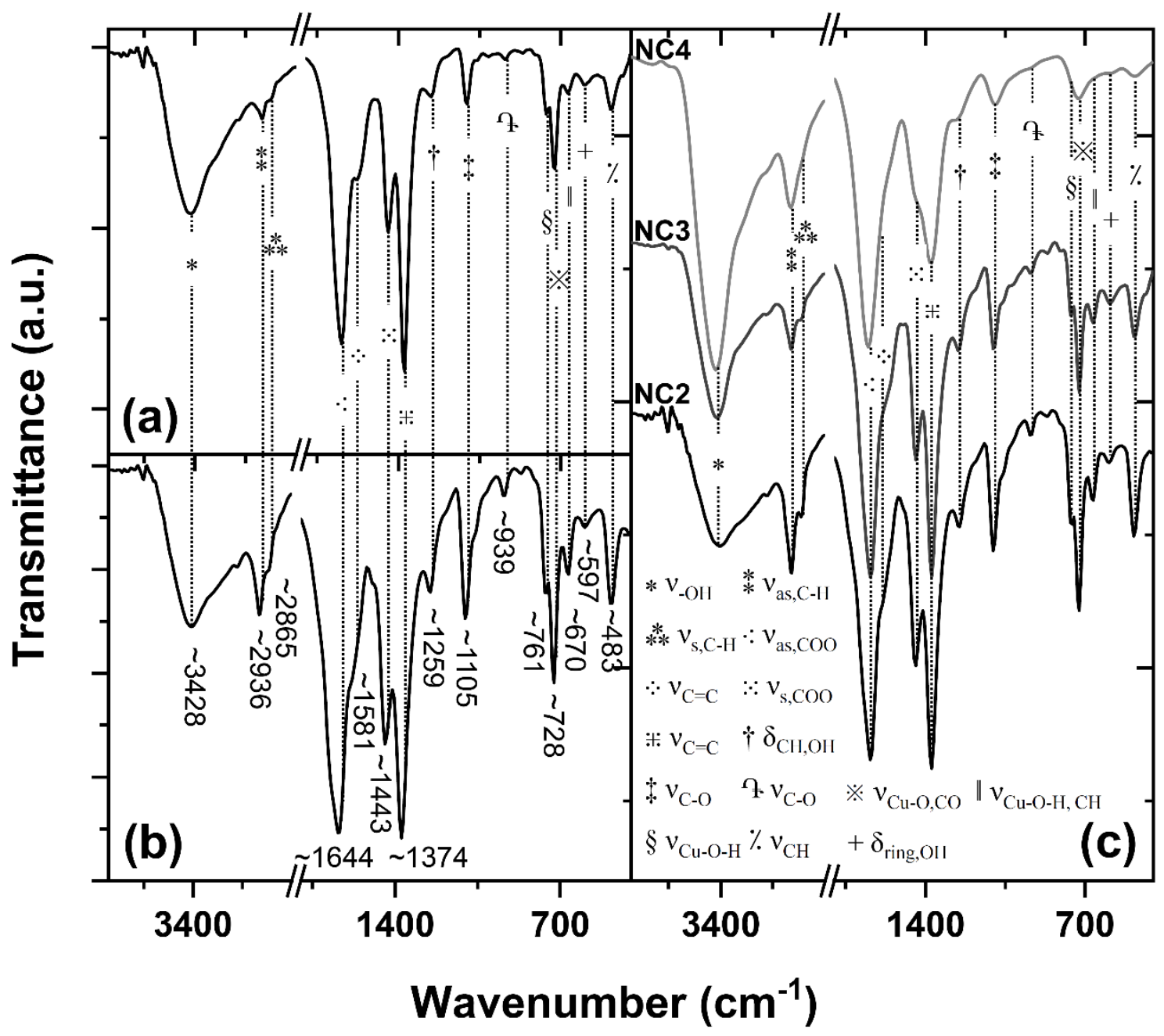

Figure 6. Surface chemistry of samples: FTIR spectra of (a) Cu-BTC NPs, (b) NC-1 (0.005 mg/ml GO), (c) $\mathrm{NC}-2(0.05 \mathrm{mg} / \mathrm{ml} \mathrm{GO}), N C-3(0.1 \mathrm{mg} / \mathrm{ml} \mathrm{GO})$ and $\mathrm{NC}-4(0.15 \mathrm{mg} / \mathrm{ml} \mathrm{GO})$ nanocomposites.

No significant difference was observed in the FTIR spectra of the neat Cu-BTC NPs (Figure 6a) and $\mathrm{Cu}-\mathrm{BTC} / \mathrm{GO}$ nanocomposites (Figure $6 \mathrm{~b}$ and c). The only difference was in the 
intensity of bands assigned to the C-H stretching vibrations (around 2916 and $2865 \mathrm{~cm}^{-1}$ ), compared to the intensity of other structural bands. The main reason for this behavior was the complete coverage of GO surface with $\mathrm{Cu}-\mathrm{BTC}$ NPs in the structure of synthesized $\mathrm{Cu}$ BTC/GO nanocomposites (see Figure 3). Moreover, no band was observed in the range of $1680-1750 \mathrm{~cm}^{-1}$ in all of the FTIR spectra, indicating the absence of free $\mathrm{H}_{3} \mathrm{BTC}$ ligands in the structure of $\mathrm{Cu}-\mathrm{BTC}$ NPs and synthesized $\mathrm{Cu}-\mathrm{BTC} / \mathrm{GO}$ nanocomposites [40].

\subsection{Raman studies}

Raman spectroscopy results were used to investigate the structural characteristics of both $\mathrm{Cu}$ BTC NPs and Cu-BTC/GO nanocomposites (Figure 7). Raman results can provide a deep understanding of the structural characteristics of Cu-BTC NPs synthesized with and without GO nanosheets in the precursor of the solvosonication process. Moreover, as $\mathrm{Cu}-\mathrm{BTC}$ NPs covered the entire surface of $\mathrm{Cu}-\mathrm{BTC} / \mathrm{GO}$ nanocomposites (see FESEM and FTIR discussions), Raman spectroscopy can be a versatile and effective tool to study the structure, defects status, and functionalities of $\mathrm{GO}$ nanosheets in synthesized $\mathrm{Cu}-\mathrm{BTC} / \mathrm{GO}$ nanocomposites [49]. 


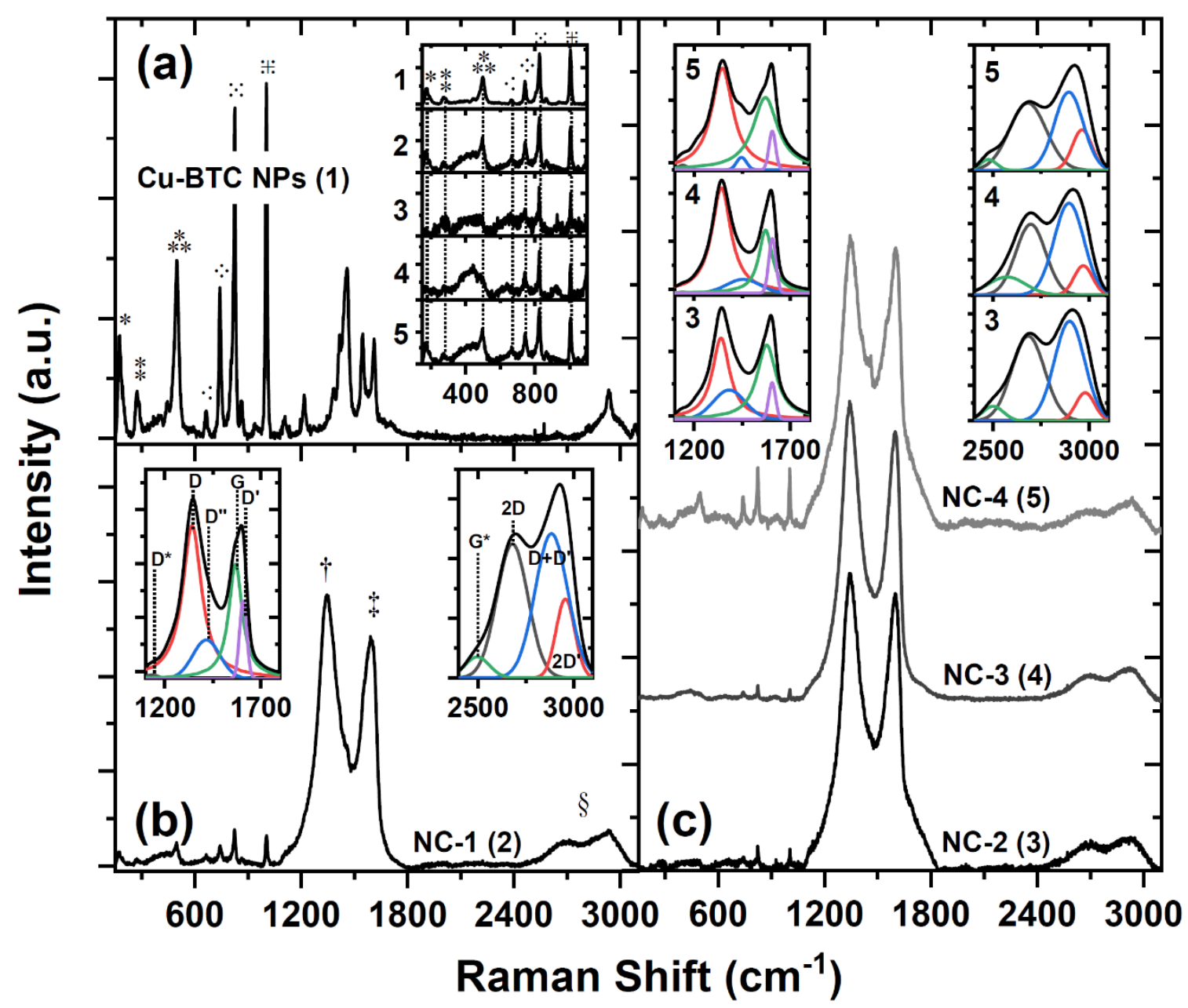

Figure 7. Structural properties: Raman spectra of (a) Cu-BTC NPs (labeled as 1), (b) NC-1 (labeled as 2), (c) NC-2 (labeled as 3), NC-3 (labeled as 4) and NC-4 (labeled as 5) nanocomposites (insets: Raman spectra of samples in 100-1100 $\mathrm{cm}^{-1}, 1100-1800 \mathrm{~cm}^{-1}$ and $2400-3100 \mathrm{~cm}^{-1}$ ranges).

Main Raman bands of synthesized Cu-BTC NPs at 177 (*), $273(*), 499$ (**), $664(\because), 741(\because)$, $826(\because), 1003$ (::), 1459, 1548 and $1611 \mathrm{~cm}^{-1}$ completely confirm the successful formation of $\mathrm{Cu}-\mathrm{BTC}$ with the mesoporous structure $[50,51]$. Raman bands at 177 and $273 \mathrm{~cm}^{-1}$ can be assigned to the $\mathrm{Cu}-\mathrm{Cu}$ dimer moieties [51]. In addition, the bands at 500 and $664 \mathrm{~cm}^{-1}$ were related to the stretching modes of $\mathrm{Cu}-\mathrm{O}$ coordination bond, and $\mathrm{Cu}_{2} \mathrm{O}$ bonding, respectively $[46,50,51]$. Two bands observed at 741 and $826 \mathrm{~cm}^{-1}$ were assigned to out-of-plane ring $\mathrm{C}-\mathrm{H}$ bending $[19,46]$. Moreover, bands at 1003 and $1611 \mathrm{~cm}^{-1}$ were related to stretching modes of $\mathrm{C}=\mathrm{C}$ bonding in the structure of $\mathrm{Cu}-\mathrm{BTC}$ NPs $[46,52]$. Furthermore, two bands observed at 1459 and $1611 \mathrm{~cm}^{-1}$ were assigned to symmetric and asymmetric vibration of $\mathrm{C}-\mathrm{O}_{2}$ bonding, respectively $[46,52]$. 
Almost no significant change was observed in the position and the relative intensity ratio of main $\mathrm{Cu}-\mathrm{BTC}$ NPs bands (the intensity ratio of bands to the intensity of the band labeled as $\because$ ) in the Raman spectra of $\mathrm{Cu}-\mathrm{BTC} / \mathrm{GO}$ nanocomposites (see the inset in Figure 7a). Moreover, $\mathrm{D}$ and $\mathrm{G}$ bands of $\mathrm{GO}$ nanosheets in the first-order Raman spectra of all synthesized $\mathrm{Cu}$ BTC/GO nanocomposites were observed at around 1350 and $1580 \mathrm{~cm}^{-1}$, respectively [53]. In addition, broad 2D bands of GO nanosheets were observed in the second-order Raman spectra of all nanocomposites at around $2700 \mathrm{~cm}^{-1}$ (Figure $7 \mathrm{~b}$ and $\mathrm{c}$ ). The intensity ratio and the position of these main bands provide information on the structural defects of GO in the structure of $\mathrm{Cu}-\mathrm{BTC} / \mathrm{GO}$ nanocomposites [54]. Moreover, fitting the shoulders of these bands can provide further information on the structural characteristics of GO in the structure of $\mathrm{Cu}$ BTC/GO nanocomposites [54].

In this work, based on the literature recommendations $[49,55]$, shoulders in the first-order Raman spectra of nanocomposites were fitted using five functions: D, G, D', D", and D* bands. As the intensity of bands related to $\mathrm{Cu}-\mathrm{BTC}$ NPs in the Raman spectra of $\mathrm{Cu}-\mathrm{BTC} / \mathrm{GO}$ nanocomposites (see the intensity of bands in Figure $7 \mathrm{~b}$ and $\mathrm{c}$ ) were much lower than that of GO-related bands, the overlapping impacts of Cu-BTC NPs bands in the $1200-1800 \mathrm{~cm}^{-1}$ region of Raman spectra in Figure $7 \mathrm{~b}$ and $\mathrm{c}$ were neglected. Moreover, the second-order Raman spectra of nanocomposites were fitted via four functions: 2D, 2D', D+D', and $\mathrm{G}^{*}$ bands [56]. Fitting parameters of first-order and second-order Raman spectra of synthesized Cu-BTC/GO nanocomposites are summarized in Figure 8. 

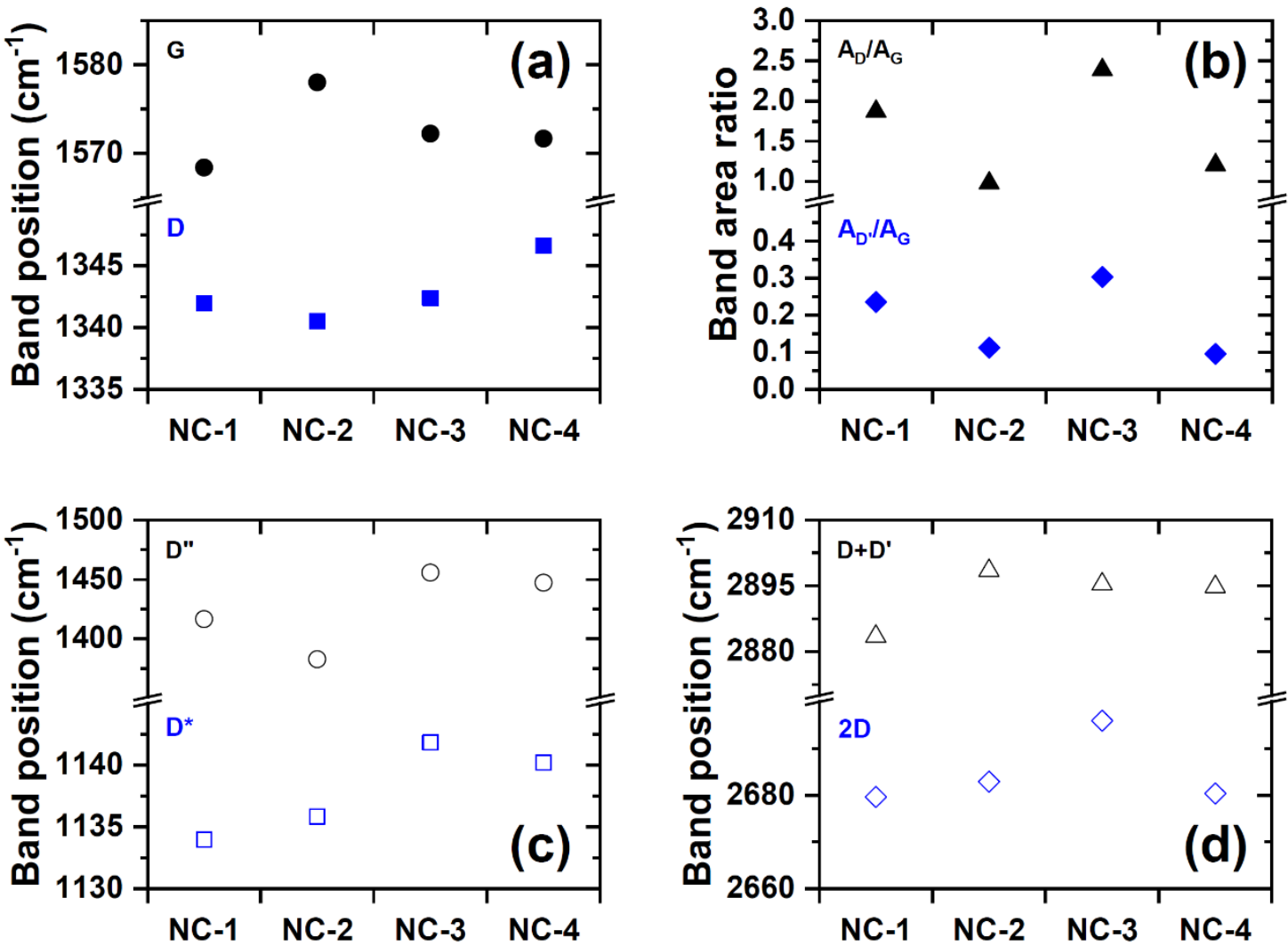

Figure 8. Fitting parameters of GO-related Raman bands: (a) position of fitted $D$ and $G$ bands, $(b) A_{D} / A_{G}$ and $A_{D} / A_{G}$ area ratios of fitted first-order Raman bands, (c) position of fitted $D^{*}$ and $D$ ' bands, and (d) position of fitted $2 D$ and $D+D$ ' second-order Raman bands of nanocomposites

The positions of G and D (also known as D1 [57]) bands and their relative intensities in the five-functions fitted Raman spectra of carbon-based materials can be considered as representatives of the graphitic structural perfectness and the disorder degree of carbon-based materials [56-58]. The $\mathrm{G}$ mode of graphite, which can lie in the range $1500-1630 \mathrm{~cm}^{-1}$, has $\mathrm{E}_{2 \mathrm{~g}}$ symmetry and represents the in-plane bond-stretching motion of pairs of $\mathrm{C} \mathrm{sp}^{2}$ atoms [55]. Moreover, the $\mathrm{D}$ band is a breathing mode of $\mathrm{A}_{1 \mathrm{~g}}$ symmetry (graphene layer edges) and only becomes active in the presence of structural disorder [55]. Therefore, the intensity ratio or the area ratio of $\mathrm{D}$ to $\mathrm{G}$ bands is expected to increase with increasing the disorder degree in the graphitic structure of carbon-based materials $[57,58]$. $A_{D} / A_{G}$ ratios lower than 3.5 are known to represent low disorder degrees in the structure of carbon-based materials (graphene edge 
disorders in particular) [57]. As a result, the $A_{D} / A_{G}$ ratios of synthesized nanocomposites in Figure $8 \mathrm{~b}$ suggest the low degrees of edge disorders in the structure of nanocomposites.

The D' band is another important first-order Raman characteristic of GO, which represents the structural disorder of graphitic lattice due to surface disorders ( $E_{2 g}$-symmetry). Features of this band can provide information on the status of surface disorders in the structure of GO nanosheets. Moreover, the $\mathrm{A}_{\mathrm{D}} / \mathrm{A}_{\mathrm{G}}$ ratio in low-defect $\mathrm{GO}$ can be considered as a measure for the type of surface disorders, with values around 0.14 for vacancies, values around 0.08 for $\mathrm{sp}^{3}$ defects (most probably surface functionalities), and values around 0.29 for grain boundaries [58]. Consequently, $\mathrm{A}_{\mathrm{D}} / \mathrm{A}_{\mathrm{G}}$ ratios calculated for nanocomposites in this work (Figure $8 \mathrm{~b}$ ) suggest that the dominant disorder type in the structure of GO nanosheets in synthesized nanocomposites was a combination of $\mathrm{sp}^{3}$ defects and grain boundaries. The observed shifts in the type of dominant surface disorder of GO nanosheets in the structure of nanocomposites can be related to the content of surface functionalities occupied by $\mathrm{Cu}-\mathrm{BTC}$ NPs through the synthesis process and as a result, the observed change in the morphology of $\mathrm{Cu}-\mathrm{BTC}$ NPs in synthesized nanocomposites (see insets in Figure 3 and XRD discussions).

The $\mathrm{D}^{*}$ band is widely considered as a representative of functionalities and ionic impurities in the structure of GO nanosheets $[57,58]$. The position of this peak is expected to shift to lower frequencies when the oxygen content in the structure increases [58]. As shown in Figure 8c, the position of this band shifted to higher wavenumbers as the content of GO nanosheets increased in the precursor solution. Since an increase in the concentration of GO nanosheets results in the presence of more oxygen-containing functional groups in the structure, this behavior should be considered as proof for interactions between surface oxygen groups of GO nanosheets and $\mathrm{Cu}$-BTC NPs in the structure of nanocomposites. Moreover, no significant and systematic change in the position of $2 \mathrm{D}$ and $\mathrm{D}+\mathrm{D}^{\prime}$ bands in Figure $8 \mathrm{~d}$ with increasing GO 
concentration in the precursor solution was observed. Therefore, it can be concluded that the percentage of $\mathrm{C} \mathrm{sp}{ }^{2}$ atoms remained unchanged, as the position of these bands can be considered as a measure of $\mathrm{C} \mathrm{sp}^{2}$ percentage in the structure of GO nanosheets [56].

The $A_{D} * / A_{G}$ ratio is a widely used measure for the content of oxygen in the structure of GObased nanostructures. Consequently, this parameter can be employed to investigate the content of functional groups on basal plane and edges of GO. The $\mathrm{A}_{\mathrm{D}} / \mathrm{A}_{\mathrm{G}}$ ratio of around $0.15 \pm 0.02$ is known to represent an oxygen percentage of $20-22 \%$ in the structure of GO nanosheets. The $\mathrm{A}_{\mathrm{D} *} / \mathrm{A}_{\mathrm{G}}$ ratio of $\mathrm{NC}-4$ was 0.16 , which was close to the $\mathrm{A}_{\mathrm{D}} * \mathrm{~A}_{\mathrm{G}}$ ratio of $\mathrm{NC}-1(0.15)$. This indicates that, despite an increase in the content of $\mathrm{GO}$ in $\mathrm{Cu}-\mathrm{BTC} / \mathrm{GO}$ nanocomposites from sample NC-1 to NC-4, oxygen containing functional groups on the basal plane and edges of GO nanosheets were probably involved in interactions with $\mathrm{Cu}-\mathrm{BTC}$ NPs.

To further investigate the possible interaction mechanism between $\mathrm{Cu}-\mathrm{BTC}$ NPs and surface functional groups on the basal plane and edges of GO, FTIR spectra of samples presented in Figure 8 were fitted via Gaussian and Lorentz functions, according to the method described in the literature (Figure S1). Fitting results were normalized to the A peak to compare the relative intensity of bands assigned to the functional groups of GO (Figure S1). Intensity ratios of FTIR fitted bands (Table S2) and the intensity ratios of Raman bands (Figure 8) were then used to investigate the role of possible interactions between GO and Cu-BTC NPs on the growth mechanism of $\mathrm{Cu}-\mathrm{BTC}$ NPs on the surface of GO nanosheets.

The nucleation of $\mathrm{Cu}-\mathrm{BTC}$ nanoparticles in the presence of $\mathrm{GO}$ nanosheets is reported to be a fast nucleation process that mainly initiates on structural defects of GO nanosheets [59]. These defects can be either molecular imperfections in the backbone of GO nanosheets (nanopores) or oxygen-containing functional groups on the basal plane of GO [59]. Moreover, the surface fluctuation of GO nanosheets, which is known to be related to the presence of functional 
groups, can further facilitate the nucleation of $\mathrm{Cu}$-BTC NPs on the surface of GO nanosheets [59]. Consequently, not only the presence of oxygen-containing functional groups on the basal plane of GO nanosheets can provide nucleation sites for the growth of $\mathrm{Cu}-\mathrm{BTC}$ NPs, these functional groups can also control the surface fluctuation of GO nanosheets [60] and as a result, the growth rate of $\mathrm{Cu}-\mathrm{BTC}$ NPs.

The suggested growth mechanism for the crystallization of Cu-BTC NPs on the surface of GO nanosheets suggest that epoxy groups on the basal plane of GO act as the seed sites for the crystallization of Cu-BTC NPs [36]. A comparison between the intensity ration of fitted bands related to the structure of $\mathrm{Cu}-\mathrm{BTC} / \mathrm{GO}$ nanocomposites prepared in this work (Table S2) suggests that an increase in the relative intensity of bands assigned to hydroxyl groups of GO nanosheets was observed in the FTIR spectra of nanocomposites with increasing the content of GO in the precursor solutions. However, no sign of bands related to epoxides and carboxyls groups of GO (expected at around 1041, 1180, and $1415 \mathrm{~cm}^{-1}$, see Figure 2) was observed in the FTIR spectra of Cu-BTC/GO nanocomposites. Since the formation of interactions between materials with carboxyls groups on the surface and $\mathrm{Cu}$-BTC NPs also reported in the literature [61], it can be concluded that molecular imperfections and the epoxides and carboxyls groups of GO acted in this work as the seed sites for the crystallization process. The growth process of $\mathrm{Cu}$-BTC NPs continued until in the $\mathrm{Cu}$-BTC nanocrystals reached a defect or other growing nanocrystals in the structure [36].

\subsection{Antibacterial properties and the role of microstructure}

Impacts of the structural characteristics of prepared samples on their antibacterial activity were investigated using the diameter of the inhabitation zone, minimum inhibitory concentration (MIC), and minimum bactericide concentration (MBC) results against $S$. aureus and E. coli 
(Figure 9), as two model bacteria that are known to be responsible for a large number of the bacterial infections among common species [1]. Cu-BTC NPs presented clear inhibition zones for both Gram-positive and Gram-negative bacteria (Figure 9a and b). The diameters of the inhabitation zone for $\mathrm{Cu}$-BTC NPs were $14 \mathrm{~mm}$ and $10 \mathrm{~mm}$ against $S$. aureus and $E$.coli bacteria, respectively (Figure 9d). This is a medium antibacterial activity compared to $\mathrm{Cu}$ based porous nanostructures with antibacterial activities in the literature [10, 12].

(a)

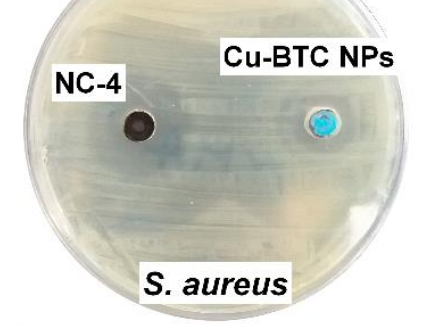

(c)
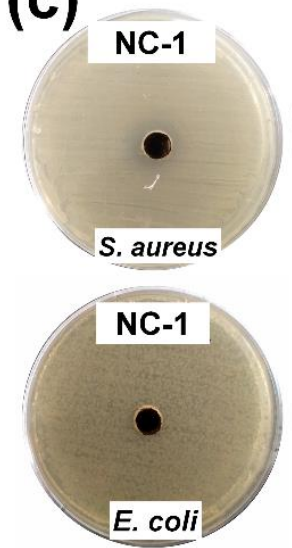

(b)

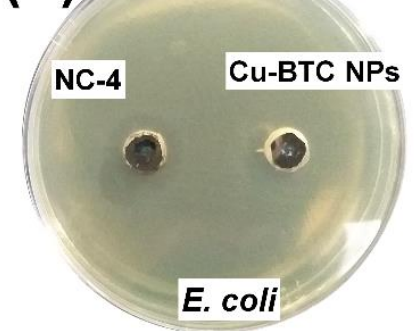

E. coli
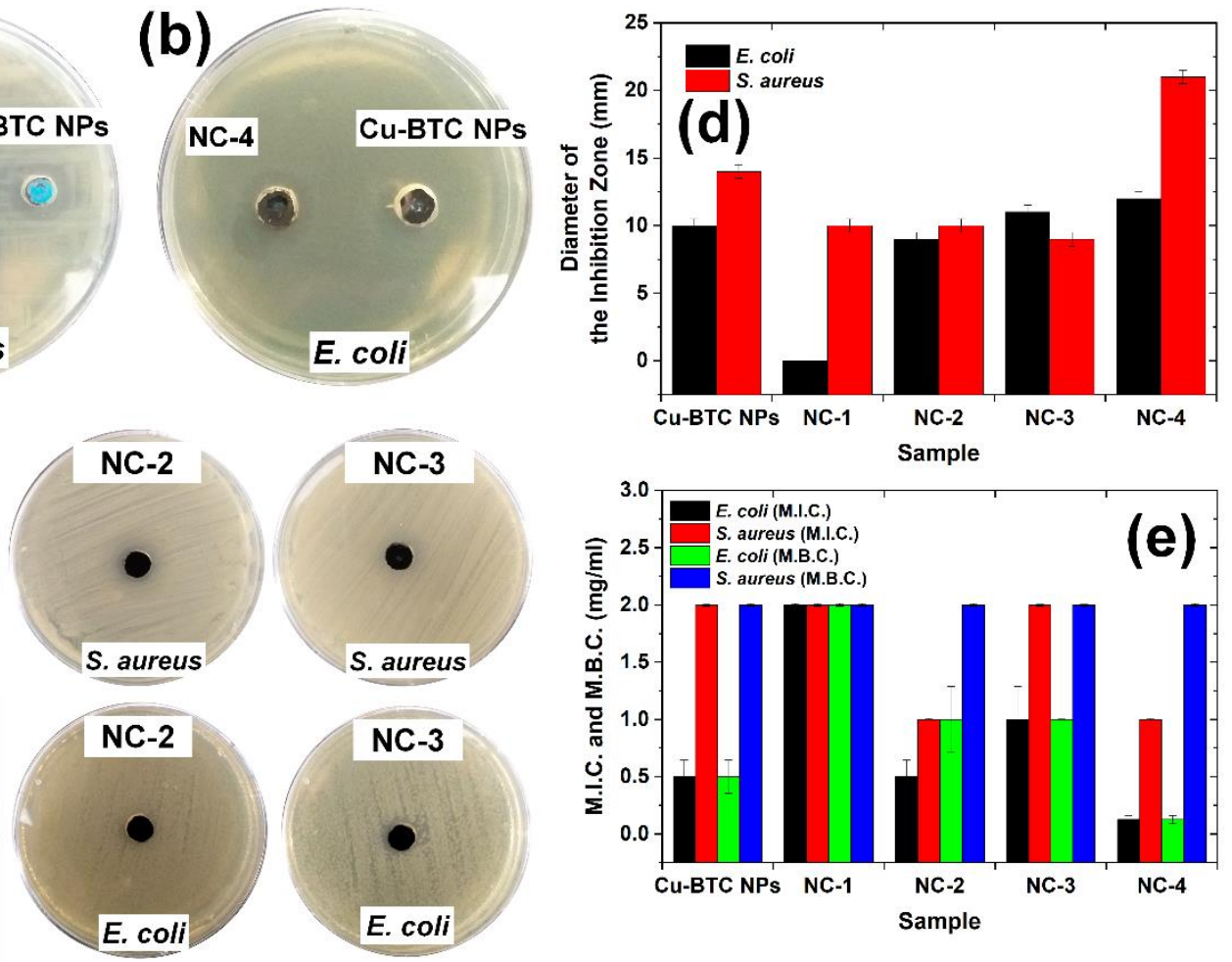

Figure 9. Antibacterial properties: formation of the inhibition zones for Cu-BTC NPs and NC-4 samples against (a) Gram-positive S. aureus (ATCC 29737) and (b) Gram-negative E. coli (ATCC 10536), inhibition zones of $N C-1, N C-2$, and $N C$-3 samples against $S$. aureus and E. coli, (d) measured diameters of the inhabitation zones of $\mathrm{Cu}-\mathrm{BTC} \mathrm{NPs}, \mathrm{NC}-1, \mathrm{NC}-2, \mathrm{NC}-3$, and $\mathrm{NC}-4$ samples against $\mathrm{S}$. aureus and E. coli at a sample concentration of $3 \mathrm{mg} / \mathrm{ml}$, (e) minimum inhibitory concentration (M.I.C.) and minimum bactericide concentration (M.B.C.) of Cu-BTC NPs, NC-1, NC-2, NC-3, and NC-4 samples against S. aureus and E. coli

The diameter of the inhabitation zone of NC-1, NC-2, and NC-3 samples against S. aureus was all lower than that of the Cu-BTC NPs sample (Figure $9 \mathrm{c}$ and d). In addition, the NC-1 sample presented no antibacterial activity against $E$. coli, even at concentrations as high as $3 \mathrm{mg} / \mathrm{ml}$. As discussed through structural studies, the main difference between NC-1 and Cu-BTC NPs samples was in the morphology of NPs. The morphology of Cu-BTC NPs synthesized in the 
presence of $0.005 \mathrm{mg} / \mathrm{mL}$ GO (NC-1) was similar to the reported morphology of $\mathrm{Cu}-\mathrm{BTC}$ MOFs. Same morphology-related antibacterial behavior against $E$. coli has been reported in the literature for $\mathrm{Cu} 2 \mathrm{O}$ crystals with different particle geometries [33].

Although the antibacterial activity of the NC-1 nanocomposite against $E$. coli was lower than the $\mathrm{Cu}$-BTC NPs, the antibacterial activity of NC-2 and NC-3 nanocomposites against $E$. coli increased with the content of GO in the precursor solution (Figure 9d). The highest antibacterial activity against both Gram-positive and Gram-negative bacteria in this work was obtained with the NC-4 sample. The diameter of the inhabitation zone of the NC-4 nanocomposite was 21 $\mathrm{mm}$ and $12 \mathrm{~mm}$ against $S$. aureus and E. coli bacteria, respectively. The lowest MIC and MBC values were also observed for the NC-4 sample (Figure 9e). Considering the discussed structural differences between fabricated samples, it can be postulated that the antibacterial activities of prepared samples were significantly affected by the morphology and the crystalline nature of Cu-based NPs.

Three main antibacterial mechanisms have been proposed in the literature for $\mathrm{Cu}$-based nanoparticles: (1) cellular uptake, (2) ion dissolution, and (3) reaction oxide species (ROS) generation [2]. In these mechanisms, the release of copper ions $\left(\mathrm{Cu}^{2+}\right.$ and $\left.\mathrm{Cu}^{+}\right)$in water plays an important and controlling role. It has been suggested that the release of copper ions increases in the presence of carbon nanotubes [8]. The same phenomena can be considered as the main reason behind the observed improved antibacterial activity of NC-4.

As discussed through FESEM, XRD, and Raman studies, the structure and the morphology of $\mathrm{Cu}-\mathrm{BTC}$ NPs synthesized in the structure of NC-4 (the highest content of GO nanosheets in the synthesis precursor solution) was similar to the structure of $\mathrm{Cu}$-BTC NPs synthesized without GO in the precursor solution. Moreover, Cu-BTC NPs synthesized without GO in the precursor solution presented a medium antibacterial activity. Furthermore, the weight 
percentage of $\mathrm{Cu}$ in the structure of the NC-4 sample was even less than the $\mathrm{Cu}-\mathrm{BTC}$ NPs sample due to the presence of GO nanosheets in the structure of the NC-4 nanocomposite. Therefore, the observed improved antibacterial activity of $\mathrm{NC}-4$ can be related to the synergistic effects of both $\mathrm{Cu}-\mathrm{BTC}$ NPs and GO nanosheets.

The antibacterial activities of both Cu-BTC NPs and NC-4 samples were higher against $S$. aureus, compared to E. coli. This behavior can be related to the presence of the bacterial outer membrane in gram-negative bacteria that improves the resistance of $E$. coli against bacteria toxicity mechanisms (Figure 10). The main proposed mechanism of the antibacterial activity of $\mathrm{Cu}$ NPs is based on the formation of $\mathrm{Cu}$ ions $\left(\mathrm{Cu}^{2+}\right.$ and $\left.\mathrm{Cu}^{+}\right)$with the release of $\mathrm{Cu}$ to the water $[8,12]$. The possible conversion of $\mathrm{Cu}^{+}$to $\mathrm{Cu}^{2+}$ in water can lead to the formation of $\mathrm{H}_{2} \mathrm{O}_{2}$, which can further facilitate the dissolution of $\mathrm{Cu}$ ions.

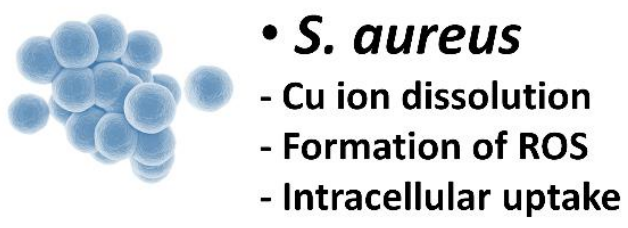

- E. coli

- Cu ion dissolution

- Formation of ROS

- Intracellular uptake

- Bacterial outer membrane

\section{Cu-BTC@ Graphene Oxide}

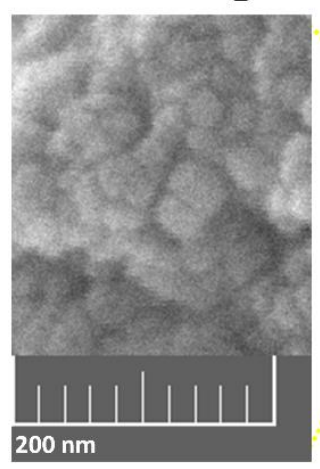

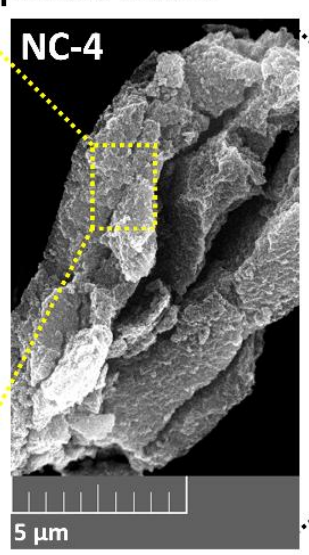

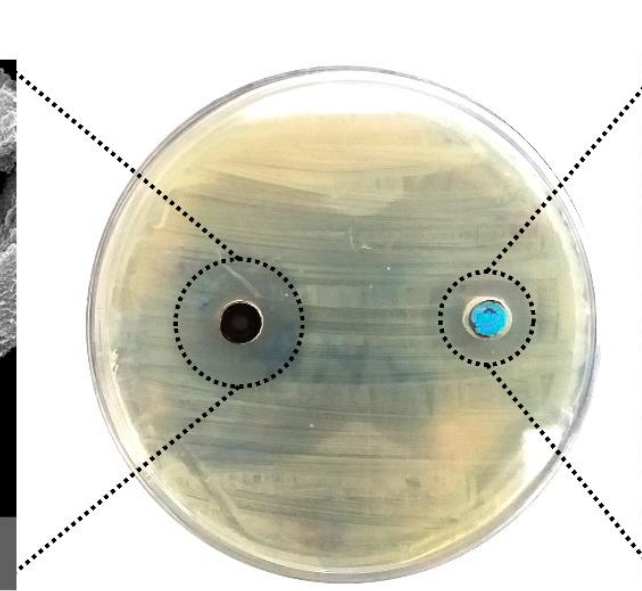

Cu-BTC NPs

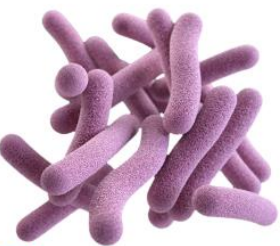


The release of $\mathrm{Cu}$ ions and the antibacterial act of such ions in water is known to be a complex reaction with a series of intermediate reactions. In proposed interaction mechanisms for the cell toxicity of cooper-based nanoparticles, the formation of $\mathrm{Cu}^{+}$is widely considered in the literature as the first possible step in the formation of copper ions $[8,62]$ :

Cu-based NPs $+\mathrm{O}_{2} \rightarrow \mathrm{Cu}^{+}+\mathrm{O}_{2}^{\cdot-}$

$\mathrm{Cu}^{+}+\mathrm{O}_{2} \rightarrow \mathrm{Cu}^{2+}+\mathrm{O}_{2}^{--}$

Moreover, the proposed interaction mechanism between copper ions and bacterial sulfhydryl groups ( $\mathrm{RSH})$ can lead to the formation of $\mathrm{H}_{2} \mathrm{O}_{2}$ and $\mathrm{ROS}[8,62]$ :

$2 \mathrm{Cu}^{2+}+2 \mathrm{RSH} \rightarrow 2 \mathrm{Cu}^{+}+\mathrm{RSSR}+2 \mathrm{H}^{+}$

$2 \mathrm{Cu}^{+}+2 \mathrm{H}^{+}+\mathrm{O}_{2} \rightarrow 2 \mathrm{Cu}^{2+}+\mathrm{H}_{2} \mathrm{O}_{2}$

$\mathrm{O}_{2}{ }^{--}+\mathrm{H}^{+} \rightarrow \mathrm{HO}_{2}{ }^{\bullet}$

$\mathrm{HO}_{2}{ }^{-}+\mathrm{H}^{+}+\mathrm{e}^{-} \rightarrow \mathrm{H}_{2} \mathrm{O}_{2}$

The hydrogen peroxide formed through equations 3-6 not only can facilitate the release of copper ions, it also assists the formation of reactive oxide species including hydroxyl radicals, which are known to have not only strong oxidizing potentials but also able to cause DNA strand breaks and affect gene expression $[8,62]$ :

$$
\begin{aligned}
& \mathrm{H}_{2} \mathrm{O}_{2}+\mathrm{O}_{2}^{--} \rightarrow \mathrm{OH}^{\bullet}+\mathrm{OH}^{-}+\mathrm{O}_{2} \\
& \mathrm{Cu}^{+}+\mathrm{H}_{2} \mathrm{O}_{2} \rightarrow \mathrm{Cu}^{2+}+\mathrm{OH}^{\cdot}+\mathrm{OH}^{-}
\end{aligned}
$$

Studies on the concentration of copper ions in the presence of bacteria suggest that the bacteria can also uptake the dissolved $\mathrm{Cu}$ ions directly [8]. $\mathrm{Cu}$ ions can damage the bacteria cell membrane and also affect the metabolic processes such as respiration osmotic stress [8]. Moreover, reactions of $\mathrm{Cu}$ ions with thiol and amino groups in proteins can lead to the 
formation of $\operatorname{ROS}[8,63]$. Oxidizing ROS radicals can also cause different damages to the bacteria, leading to the bacteria cell toxicity [8].

In addition to the important aforementioned impacts of the released coper ions on main cellular toxicity mechanisms of $\mathrm{Cu}$-BTC NPs, i.e. direct cellular uptake of copper ions, formation of reaction oxide species, and damages to the bacterial membrane, the role of GO nanosheets on the high antibacterial performance of $\mathrm{Cu}-\mathrm{BTC} / \mathrm{GO}$ nanocomposites should also be addressed. GO is known to have the highest antibacterial activity among different graphene-based materials (i.e., graphite, graphite oxide, GO and reduced-GO) [64]. Sharpe edges of GO nanosheets can cause irreversible damages to the bacterial cell [64]. Moreover, oxygencontaining functional groups on the basal plane and edges of GO can not only improve the formation of ROS but also affect microbial processes by disturbing the cellular structure [64]. Consequently, the observed improved antibacterial performance of the NC-4 sample, compared to the $\mathrm{Cu}-\mathrm{BTC}$ sample, can be related to the additional cellular toxicity of the NC-4 sample caused by the presence of GO nanosheets in the structure.

\section{Conclusions}

In this work, $\mathrm{Cu}-\mathrm{BTC} / \mathrm{GO}$ nanocomposites with different morphologies and structures were synthesized through the solvothermal synthesis of Cu-BTC NPs in the presence of different contents of GO nanosheets. The nucleation and growth of Cu-BTC NPs took place on the basal plane of GO nanosheets and therefore, the size and morphology of the synthesized Cu-BTC NPs in the structure of $\mathrm{Cu}-\mathrm{BTC} / \mathrm{GO}$ nanocomposites were directly related to the content of GO nanosheets in the precursor solution.

The size range of $\mathrm{Cu}-\mathrm{BTC}$ NPs changed from 30-40 nm to $15-20 \mathrm{~nm}$ when the content of GO nanosheets in the precursor solution increased from 0.005 to $0.15 \mathrm{mg} / \mathrm{ml}$. Moreover, Raman 
and XRD results revealed that the structural characteristics of $\mathrm{Cu}-\mathrm{BTC}$ NPs were also related to the GO content in the precursor solution. The microstructure of the $\mathrm{Cu}-\mathrm{BTC} / \mathrm{GO}$ nanocomposite synthesized with $0.15 \mathrm{mg} / \mathrm{ml}$ of $\mathrm{GO}$ in the precursor solution (NC-4) became similar to the Cu-BTC NPs sample synthesized without GO. We suggested that the content of available sites for the nucleation of the $\mathrm{Cu}$-BTC crystals increased with the increase of the GO content in the precursor solution, and as a result, $\mathrm{Cu}$-BTC NPs with smaller nanoparticle size ranges were obtained in the structure of the NC-4 sample.

Interestingly, antibacterial studies against $S$. aureus and $E$. coli suggested that the antibacterial activity of $\mathrm{Cu}-\mathrm{BTC} / \mathrm{GO}$ nanocomposites increased with the decrease of $\mathrm{Cu}-\mathrm{BTC}$ nanoparticle size, and the largest diameter of the inhabitation zone for both studied bacteria was observed for the NC-4 sample. Our results confirmed that the antibacterial activity of $\mathrm{Cu}-\mathrm{BTC} / \mathrm{GO}$ nanocomposites can be controlled by tuning the structural and morphological properties of $\mathrm{Cu}$ BTC NPs through the synthesis process.

\section{References}

[1] X. Ren, C. Yang, L. Zhang, S. Li, S. Shi, R. Wang, X. Zhang, T. Yue, J. Sun, J. Wang, Copper metal-organic frameworks loaded on chitosan film for the efficient inhibition of bacteria and local infection therapy, Nanoscale, 11 (2019) 11830-11838.

[2] P. Rajapaksha, S. Cheeseman, S. Hombsch, B.J. Murdoch, S. Gangadoo, E.W. Blanch, Y. Truong, D. Cozzolino, C.F. McConville, R.J. Crawford, V.K. Truong, A. Elbourne, J. Chapman, Antibacterial Properties of Graphene Oxide-Copper Oxide Nanoparticle Nanocomposites, ACS Appl. Bio Mater., 2 (2019) 5687-5696. 
[3] S.V. Gudkov, D.E. Burmistrov, D.A. Serov, M.B. Rebezov, A.A. Semenova, A.B. Lisitsyn, A Mini Review of Antibacterial Properties of $\mathrm{ZnO}$ Nanoparticles, Frontiers in Physics, 9 (2021)

[4] Z. Guo, Y. Chen, Y. Wang, H. Jiang, X. Wang, Advances and challenges in metallic nanomaterial synthesis and antibacterial applications, J. Mater. Chem. B, 8 (2020) 4764-4777. [5] T. Munawar, F. Mukhtar, M.S. Nadeem, K. Mahmood, M. Hasan, A. Hussain, A. Ali, M.I. Arshad, F. Iqbal, Novel direct dual-Z-scheme ZnO-Er2O3-Nd2O3@ reduced graphene oxide heterostructured nanocomposite: Synthesis, characterization and superior antibacterial and photocatalytic activity, Materials Chemistry and Physics, 253 (2020) 123249.

[6] M.S. Selim, N.A. Samak, Z. Hao, J. Xing, Facile design of reduced graphene oxide decorated with $\mathrm{Cu} 2 \mathrm{O}$ nanocube composite as antibiofilm active material, Materials Chemistry and Physics, 239 (2020) 122300.

[7] Y. Lv, L. Li, P. Yin, T. Lei, Synthesis and evaluation of the structural and antibacterial properties of doped copper oxide, Dalton Trans., 49 (2020) 4699-4709.

[8] T. Huang, M. Sui, J. Li, Inactivation of E. coli by nano-Cu/MWCNTs combined with hydrogen peroxide, Sci. Total Environ., 574 (2017) 818-828.

[9] A. Rauf, J. Ye, S. Zhang, Y. Qi, G. Wang, Y. Che, G. Ning, Copper(ii)-based coordination polymer nanofibers as a highly effective antibacterial material with a synergistic mechanism, Dalton Trans., 48 (2019) 17810-17817.

[10] M. Shen, F. Forghani, X. Kong, D. Liu, X. Ye, S. Chen, T. Ding, Antibacterial applications of metal-organic frameworks and their composites, Compr. Rev. Food Sci. F., 19 (2020) 13971419.

[11] G. Wyszogrodzka, B. Marszałek, B. Gil, P. Dorożyński, Metal-organic frameworks: mechanisms of antibacterial action and potential applications, Drug Discov. Today, 21 (2016) 1009-1018. 
[12] S. Shams, W. Ahmad, A.H. Memon, S. Shams, Y. Wei, Q. Yuan, H. Liang, Cu/H3BTC MOF as a potential antibacterial therapeutic agent against Staphylococcus aureus and Escherichia coli, New J. Chem., 44 (2020) 17671-17678.

[13] J. Meng, X. Liu, C. Niu, Q. Pang, J. Li, F. Liu, Z. Liu, L. Mai, Advances in metal-organic framework coatings: versatile synthesis and broad applications, Chem. Soc. Rev., 49 (2020) $3142-3186$.

[14] S.-J. Wang, F. Bigdeli, X.-W. Yan, L. Esrafili, K.-G. Liu, H. Ghasempour, X.-Q. Cai, M.L. Hu, A. Morsali, Synthesis of a new binuclear $\mathrm{Cu}(\mathrm{II})$ complex: A precise sensor for $\mathrm{H} 2 \mathrm{O} 2$ and a proper precursor for preparation of the $\mathrm{CuO}$ nanoparticles, Journal of Organometallic Chemistry, 926 (2020) 121507.

[15] J. Li, H. Wang, X. Yuan, J. Zhang, J.W. Chew, Metal-organic framework membranes for wastewater treatment and water regeneration, Coord. Chem. Rev., 404 (2020) 213116.

[16] M. Gu, M. Wu, S.-C. Wang, C. Chen, D. Xiong, F.-Y. Yi, Morphology control of nanoscale metal-organic frameworks for high-performance supercapacitors, Electrochim. Acta, 343 (2020) 135617.

[17] S.-M. Hwang, S.Y. Choi, M.H. Youn, W. Lee, K.T. Park, K. Gothandapani, A.N. Grace, S.K. Jeong, Investigation on Electroreduction of $\mathrm{CO} 2$ to Formic Acid Using $\mathrm{Cu} 3(\mathrm{BTC}) 2$ Metal-Organic Framework (Cu-MOF) and Graphene Oxide, ACS Omega, 5 (2020) 2391923930.

[18] M.H. Norahan, M. Pourmokhtari, M.R. Saeb, B. Bakhshi, M. Soufi Zomorrod, N. Baheiraei, Electroactive cardiac patch containing reduced graphene oxide with potential antibacterial properties, Mater. Sci. Eng. C, 104 (2019) 109921.

[19] T. Shen, T. Liu, H. Mo, Z. Yuan, F. Cui, Y. Jin, X. Chen, Cu-based metal-organic framework HKUST-1 as effective catalyst for highly sensitive determination of ascorbic acid, RSC Adv., 10 (2020) 22881-22890. 
[20] A. Allahbakhsh, PVC/rice straw/SDBS-modified graphene oxide sustainable Nanocomposites: Melt mixing process and electrical insulation characteristics, Compos. Part A Appl. Sci. Manuf., 134 (2020) 105902.

[21] A. Allahbakhsh, S. Yari, M. Safari, D.P. Dubal, Poly(ethylene disulfide)/graphene oxide nanocomposites: Dynamic-mechanical and electrochemical properties, Eur. Polym. J., 130 (2020) 109694.

[22] S. Jovanović, I. Holclajtner-Antunović, S. Uskoković-Marković, D. Bajuk-Bogdanović, V. Pavlović, D. Tošić, M. Milenković, B. Todorović Marković, Modification of graphene oxide surfaces with 12-molybdophosphoric acid: Structural and antibacterial study, Materials Chemistry and Physics, 213 (2018) 157-167.

[23] S. Sadhukhan, A. Bhattacharyya, D. Rana, T.K. Ghosh, J.T. Orasugh, S. Khatua, K. Acharya, D. Chattopadhyay, Synthesis of RGO/NiO nanocomposites adopting a green approach and its photocatalytic and antibacterial properties, Materials Chemistry and Physics, 247 (2020) 122906.

[24] M. Khalaj, A. Allahbakhsh, A.R. Bahramian, A. Sharif, Structural, mechanical and thermal behaviors of novolac/graphene oxide nanocomposite aerogels, J. Non-Cryst. Solids, 460 (2017) 19-28.

[25] A. Allahbakhsh, A.R. Bahramian, Self-assembly of graphene quantum dots into hydrogels and cryogels: Dynamic light scattering, UV-Vis spectroscopy and structural investigations, J. Mol. Liq., 265 (2018) 172-180.

[26] A. Allahbakhsh, Nitrogen-doped graphene quantum dots hydrogels for highly efficient solar steam generation, Desalination, 517 (2021).

[27] A. Allahbakhsh, F. Noei Khodabadi, F.S. Hosseini, A.H. Haghighi, 3-Aminopropyltriethoxysilane-functionalized rice husk and rice husk ash reinforced polyamide 6/graphene oxide sustainable nanocomposites, Eur. Polym. J., 94 (2017) 417-430. 
[28] P. Arul, S. Abraham John, Electrodeposition of $\mathrm{CuO}$ from $\mathrm{Cu}-\mathrm{MOF}$ on glassy carbon electrode: A non-enzymatic sensor for glucose, J. Electroanal. Chem., 799 (2017) 61-69.

[29] A.R. Abbasi, M. Karimi, K. Daasbjerg, Efficient removal of crystal violet and methylene blue from wastewater by ultrasound nanoparticles $\mathrm{Cu}-\mathrm{MOF}$ in comparison with mechanosynthesis method, Ultrason. Sonochem., 37 (2017) 182-191.

[30] D.G. Atinafu, S.J. Chang, U. Berardi, K.-H. Kim, S. Kim, Potential utility of HKUST-1graphite nanocomposite to endow alkane with high thermal properties and low electrical resistivity, J. Hazard. Mater., 402 (2021) 123695.

[31] N. Bhoria, G. Basina, J. Pokhrel, K.S. Kumar Reddy, S. Anastasiou, V.V. Balasubramanian, Y.F. AlWahedi, G.N. Karanikolos, Functionalization effects on HKUST-1 and HKUST-1/graphene oxide hybrid adsorbents for hydrogen sulfide removal, J. Hazard. Mater., 394 (2020) 122565.

[32] Q.V. Thi, N.Q. Nguyen, I. Oh, J. Hong, C.M. Koo, N.T. Tung, D. Sohn, Thorny trunklike structure of reduced graphene oxide/HKUST-1 MOF for enhanced EMI shielding capability, Ceram. Int., 47 (2020) 10027-10034.

[33] B. Li, Y. Li, Y. Zhao, L. Sun, Shape-controlled synthesis of Cu2O nano/microcrystals and their antibacterial activity, J. Phys. Chem. Solids, 74 (2013) 1842-1847.

[34] S. Shang, Z. Tao, C. Yang, A. Hanif, L. Li, D.C.W. Tsang, Q. Gu, J. Shang, Facile synthesis of CuBTC and its graphene oxide composites as efficient adsorbents for $\mathrm{CO} 2$ capture, Chem. Eng. Technol., 393 (2020) 124666.

[35] F. Israr, D.K. Kim, Y. Kim, S.J. Oh, K.C. Ng, W. Chun, Synthesis of porous Cu-BTC with ultrasonic treatment: Effects of ultrasonic power and solvent condition, Ultrason. Sonochem., 29 (2016) 186-193. 
[36] S. Liu, L. Sun, F. Xu, J. Zhang, C. Jiao, F. Li, Z. Li, S. Wang, Z. Wang, X. Jiang, H. Zhou, L. Yang, C. Schick, Nanosized Cu-MOFs induced by graphene oxide and enhanced gas storage capacity, Energy Environ. Sci., 6 (2013) 818.

[37] A.M.P. Peedikakkal, I.H. Aljundi, Mixed-Metal Cu-BTC Metal-Organic Frameworks as a Strong Adsorbent for Molecular Hydrogen at Low Temperatures, ACS Omega, 5 (2020) 28493-28499.

[38] M.Ş.A. Eren, H. Arslanoğlu, H. Çiftçi, Production of microporous Cu-doped BTC (CuBTC) metal-organic framework composite materials, superior adsorbents for the removal of methylene blue (Basic Blue 9), Journal of Environmental Chemical Engineering, 8 (2020).

[39] R.M. Abdelhameed, H.E. Emam, J. Rocha, A.M.S. Silva, Cu-BTC metal-organic framework natural fabric composites for fuel purification, Fuel Process. Technol., 159 (2017) 306-312.

[40] Y. Liu, P. Ghimire, M. Jaroniec, Copper benzene-1,3,5-tricarboxylate (Cu-BTC) metalorganic framework (MOF) and porous carbon composites as efficient carbon dioxide adsorbents, J. Colloid Interface Sci., 535 (2019) 122-132.

[41] Y. Sun, M. Ma, B. Tang, S. Li, L. Jiang, X. Sun, M. Que, C. Tao, Z. Wu, Graphene modified $\mathrm{Cu}-\mathrm{BTC}$ with high stability in water and controllable selective adsorption of various gases, J. Alloys Compd., 808 (2019) 151721.

[42] Y. Mao, L. shi, H. Huang, W. Cao, J. Li, L. Sun, X. Jin, X. Peng, Room temperature synthesis of free-standing HKUST-1 membranes from copper hydroxide nanostrands for gas separation, Chem. Commun., 49 (2013) 5666.

[43] A. Allahbakhsh, A.H. Haghighi, M. Sheydaei, Poly(ethylene trisulfide)/graphene oxide nanocomposites, J. Therm. Anal. Calorim., 128 (2016) 427-442. 
[44] M.R. Azhar, H.R. Abid, H. Sun, V. Periasamy, M.O. Tadé, S. Wang, Excellent performance of copper based metal organic framework in adsorptive removal of toxic sulfonamide antibiotics from wastewater, J. Colloid Interface Sci., 478 (2016) 344-352. [45] P. Tan, X.-Y. Xie, X.-Q. Liu, T. Pan, C. Gu, P.-F. Chen, J.-Y. Zhou, Y. Pan, L.-B. Sun, Fabrication of magnetically responsive HKUST-1/Fe3O4 composites by dry gel conversion for deep desulfurization and denitrogenation, J. Hazard. Mater., 321 (2017) 344-352.

[46] X. Li, C. Li, C. Wu, K. Wu, Strategy for Highly Sensitive Electrochemical Sensing: In Situ Coupling of a Metal-Organic Framework with Ball-Mill-Exfoliated Graphene, Anal. Chem., 91 (2019) 6043-6050.

[47] S. Yang, Q. Zou, T. Wang, L. Zhang, Effects of GO and MOF@GO on the permeation and antifouling properties of cellulose acetate ultrafiltration membrane, J. Membr. Sci., 569 (2019) 48-59.

[48] M.B. Nguyen, V.T. Hong Nhung, V.T. Thu, D.T. Ngoc Nga, T.N. Pham Truong, H.T. Giang, P.T. Hai Yen, P.H. Phong, T.A. Vu, V.T. Thu Ha, An electrochemical sensor based on copper-based metal-organic framework-reduced graphene oxide composites for determination of 2,4-dichlorophenol in water, RSC Adv., 10 (2020) 42212-42220.

[49] A.C. Ferrari, D.M. Basko, Raman spectroscopy as a versatile tool for studying the properties of graphene, Nat. Nanotechnol., 8 (2013) 235-246.

[50] X. Deng, R. Li, S. Wu, L. Wang, J. Hu, J. Ma, W. Jiang, N. Zhang, X. Zheng, C. Gao, L. Wang, Q. Zhang, J. Zhu, Y. Xiong, Metal-Organic Framework Coating Enhances the Performance of Cu2O in Photoelectrochemical CO2 Reduction, J. Am. Chem. Soc., 141 (2019) 10924-10929.

[51] R. Nivetha, A. Sajeev, A. Mary Paul, K. Gothandapani, S. Gnanasekar, P. Bhardwaj, G. Jacob, R. Sellappan, V. Raghavan, K.C. N, S. Pitchaimuthu, S.K. Jeong, A. Nirmala Grace, Cu 
based Metal Organic Framework (Cu-MOF) for electrocatalytic hydrogen evolution reaction, Mater. Res. Express, 7 (2020) 114001.

[52] P. Arul, N.S.K. Gowthaman, S.A. John, M. Tominaga, Tunable electrochemical synthesis of 3D nucleated microparticles like $\mathrm{Cu}-\mathrm{BTC}$ MOF-carbon nanotubes composite: Enzyme free ultrasensitive determination of glucose in a complex biological fluid, Electrochim. Acta, 354 (2020) 136673.

[53] A. Allahbakhsh, A.R. Bahramian, Novolac-derived carbon aerogels pyrolyzed at high temperatures: experimental and theoretical studies, RSC Adv., 6 (2016) 72777-72790.

[54] P. Vecera, J.C. Chacón-Torres, T. Pichler, S. Reich, H.R. Soni, A. Görling, K. Edelthalhammer, H. Peterlik, F. Hauke, A. Hirsch, Precise determination of graphene functionalization by in situ Raman spectroscopy, Nat. Commun., 8 (2017) 15192.

[55] A.C. Ferrari, J. Robertson, Interpretation of Raman spectra of disordered and amorphous carbon, Phys. Rev. B, 61 (2000) 14095-14107.

[56] D. López-Díaz, M. López Holgado, J.L. García-Fierro, M.M. Velázquez, Evolution of the Raman Spectrum with the Chemical Composition of Graphene Oxide, J. Phys. Chem. C, 121 (2017) 20489-20497.

[57] A. Sadezky, H. Muckenhuber, H. Grothe, R. Niessner, U. Pöschl, Raman microspectroscopy of soot and related carbonaceous materials: Spectral analysis and structural information, Carbon, 43 (2005) 1731-1742.

[58] D. López-Díaz, J.A. Delgado-Notario, V. Clericò, E. Diez, M.D. Merchán, M.M. Velázquez, Towards Understanding the Raman Spectrum of Graphene Oxide: The Effect of the Chemical Composition, Coatings, 10 (2020) 524.

[59] K.S. Song, D. Kim, A. Coskun, Hierarchically Porous Reduced Graphene Oxide Coated with Metal-Organic Framework HKUST-1 for Enhanced Hydrogen Gas Affinity, ACS Applied Nano Materials, 3 (2019) 985-991. 
[60] A. Allahbakhsh, F. Sharif, S. Mazinani, The Influence of Oxygen-Containing Functional Groups on the Surface Behavior and Roughness Characteristics of Graphene Oxide, Nano, 08 (2013).

[61] P. Küsgens, S. Siegle, S. Kaskel, Crystal Growth of the Metal-Organic Framework Cu3(BTC)2on the Surface of Pulp Fibers, Advanced Engineering Materials, 11 (2009) 93-95. [62] B. Joshi, C. Regmi, D. Dhakal, G. Gyawali, S.W. Lee, Efficient inactivation of Staphylococcus aureus by silver and copper loaded photocatalytic titanate nanotubes, Progress in Natural Science: Materials International, 28 (2018) 15-23.

[63] M.E. Letelier, A.M. Lepe, M. Faúndez, J. Salazar, R. Marín, P. Aracena, H. Speisky, Possible mechanisms underlying copper-induced damage in biological membranes leading to cellular toxicity, Chem.-Biol. Interact., 151 (2005) 71-82.

[64] S. Liu, T.H. Zeng, M. Hofmann, E. Burcombe, J. Wei, R. Jiang, J. Kong, Y. Chen, Antibacterial Activity of Graphite, Graphite Oxide, Graphene Oxide, and Reduced Graphene Oxide: Membrane and Oxidative Stress, ACS Nano, 5 (2011) 6971-6980. 